\title{
Engineering Nanostructures of PGM-Free Oxygen-Reduction Catalysts Using
}

\section{Metal-Organic Frameworks}

\author{
Hanguang Zhang ${ }^{\mathrm{a}}$, Hannah Osgood ${ }^{\mathrm{a}}$, Xiaohong Xie, \\ Yuyan Shao, ${ }^{\mathrm{b}, *}$ and Gang $\mathrm{Wu}^{\mathrm{a}, *}$ \\ ${ }^{a}$ Department of Chemical and Biological Engineering, University at Buffalo, The State \\ University of New York, Buffalo, NY 14260, United States \\ ${ }^{\mathrm{b}}$ Pacific Northwest National Laboratory, Richland, WA 99352, United States
}

\begin{abstract}
Oxygen reduction reaction (ORR) is one of the essential electrochemical reactions for the energy conversion and storage devices such as fuel cells and metal-air batteries. However, a large amount of $\mathrm{Pt}$ is required for catalyzing the kinetically sluggish ORR at the air cathode, therefore greatly limiting their large scale implementation. Development of high-performance platinum group-metal (PGM)-free ORR catalysts has been a long-term goal for such clean energy technologies. However, current PGM-free catalysts are still significantly suffering from insufficient activity and limited durability especially in more challenging acidic media, such as proton exchange membranes (PEM) fuel cells. Recently, metal-organic frameworks (MOFs), constructed from bridging metal ions and ligands, have emerged as a new type of attractive precursors for the synthesis of PGM-free catalysts, which has led to encouraging performance improvement. Compared to other catalyst precursors, MOFs have well-defined crystal structure with tunable chemistry and contain all required elements (e.g., carbon, nitrogen, and metal). Here, we provide an account of recent innovative PGM-free catalyst design and synthesis derived from the unique MOF precursors with special emphasis on engineering nanostructure and morphology of catalysts. We aim to provide new insights into the design and synthesis of advanced PGM-free
\end{abstract}


catalysts with increased density of active sites and controlled bonding in 3D frame network. In addition, we also discuss the possibility to use the well-defined MOF precursors for building up model systems to elucidate the structure-property correlations of catalysts and the nature of active sites.

\section{Contents}

1. Introduction

2. General approach to design MOF-derived catalysts

2.1. MOF precursors

2.2. Metal and ligand precursors

2.3. General synthesis approaches

3. Catalysts derived from MOF crystals

3.1. MOF crystal precursors containing single inactive metal ions

3.2. M-N-C catalysts derived from MOFs with single active metals

3.3. MOF crystals containing binary metal ions

3.3.1. $\mathrm{Co} / \mathrm{Zn}$ containing MOF crystals-derived catalysts

3.3.2. Fe/Zn containing MOF crystals-derived catalysts

4. Catalysts derived from MOF hybrid precursors

4.1. N-C catalysts derived from MOF hybrid precursors

4.2. M-N-C catalysts derived from MOF hybrid precursors

5. Catalysts derived from supported MOF crystal composite precursors

5.1. Nanocarbon supported MOF crystals hybrid

5.2. Non-carbon Templates

6. Summary and perspective 


\section{Introduction}

Fuel cells, generating electricity via converting chemical energy from hydrogen and oxygen with only water as a product, has become one of the most promising alternatives to traditional combustion engines for transportation applications [1]. The first commercial fuel cell vehicle has been introduced in 2014. Two electrochemical reactions are involved in fuel cells: the hydrogen oxidation reaction (HOR) and oxygen reduction reaction (ORR). HOR can easily take place on Pt in acid media to quickly generate high current density at the anode. However, the ORR at the cathode is kinetically sluggish, nearly five orders of magnitude slower even using Pt catalysts [2, 3]. ORR is a complex reaction and involves four electron transfer with complicated mechanisms that are associated with a number of adsorption, dissociation, recombination, and desorption of oxygen containing intermediates. As a result, although high Pt loadings are used on the cathode

(e.g., $0.2 \mathrm{mg} \mathrm{Pt}_{\mathrm{P}} / \mathrm{cm}^{2}$ ), generating decent current density is required a high ORR overpotential of more than $300 \mathrm{mV}$ [4, 5], which significantly reduces the energy conversion efficiency. Therefore, the insufficient activity along with its great dependence of scarce Pt on earth, the ORR is indeed the bottleneck for high performance fuel cells. In parallel to the development of low-platinum group-metal (PGM) catalyst with continuously increased activity and durability [611], significant effort has been on PGM-free ORR electrocatalysis in the past decade, which has results in great progress [12-17]. Compared to other studied oxides, sulfides, and carbides [1824], carbon-based catalysts have many obvious advantages including low cost, high electrical conductivity, high surface areas, easy functionalities and processibility $[25,26]$. Therefore, carefully engineering nanostructure, morphology, and doping of carbon materials would yield high performance PGM-free ORR catalysts with significantly increased density of active sites and strengthened bonding structures. 
Inspired by the catalytic activity of a macrocyclic compound comprising $\mathrm{M}-\mathrm{N}_{4}(\mathrm{M}: \mathrm{Fe}$ or $\mathrm{Co}$ ) coordination discovered in 1964 [27], scientists initially focused on the development of macrocycle-based ORR catalysts by using high temperature treatment to improve the stability and activity [28]. This opened a new approach to synthesize PGM-free ORR catalysts with numerous choices of precursors [29]. Later, instead of expensive macrocyclic compounds, a wide variety of nitrogen and carbon precursors (e.g., ethylene diamine, polypyrrole, polyaniline, and melamine), along with inexpensive inorganic transition metal salts were identified as effective to yield active metal-nitrogen-carbon (M-N-C) catalysts [13, 30-41]. Meanwhile, the understanding of active sites on such-synthesized PGM-free catalysts through high temperature treatments has also been focused on heteroatom-doped (e.g., N, B, S or P) carbon structures and the possible coordination between metal and nitrogen [20, 42-48]. Transition metals (Fe/Co) have been recognized to play a significant role in the formation of active sites during high temperature treatments $[41,49,50]$. It is still unclear whether metal elements act as active sites for ORR or they are just involved in the formation of active sites of nitrogen-doped carbon $(\mathrm{N}-$ doped carbon) [51]. However, recent modeling simulation results tends to support that the $\mathrm{FeN}_{4}$ moiety embedded into carbon plane is likely the active sites with favorable binding energy for $\mathrm{O}_{2}$ adsorption and $\mathrm{O}=\mathrm{O}$ bond dissociation during the $\mathrm{ORR}$ [52-54]. Due to highly heterogeneous morphologies in such-synthesized catalysts, current characterization, even including advanced X-ray absorption and Mössbauer, is not able to verify the proposed chemical formulation of active sites $[55,56]$. The optimization of catalyst synthesis such as screening of different precursors and temperature optimization of pyrolysis as well as correlating the structureperformance relationship of catalysts have led to many highly active M-N-C catalysts [14, 49, 57-63]. However, the lack of well-controlled synthetic chemistry techniques remains a major 
challenge to significantly increase density of active sites and strengthen the bonding structures in catalysts, and more importantly to understand the nature of active sites, which are important to developing rules for PGM-free catalyst design and synthesis. Currently, in most traditional synthesis methods of M-N-C catalysts, all precursors are typically mixed together into a complex composite for high temperature treatment, resulting in uncontrolled structures and highly heterogeneous aggregates. This further makes it difficult to study the structure-property correlations to identify active sites and elucidate their formation mechanism during pyrolysis.

Metal-organic frameworks (MOFs), constructed by bridging metal-containing units with organic linkers to create ordered crystal frameworks, have attracted interest in many fields such as gas storage, gas separation, drug delivery, and energy storage and conversion due to their well-defined crystal structure, large surface area, high volume of tunable micropores, and variety in synthetic chemistry [64-66]. High surface area and microporous carbon materials can be easily obtained by carbonization of MOFs at high temperatures [67-69]. In comparison to the traditional synthesis of M-N-C catalysts, MOFs are ideal precursors that integrate metal, nitrogen and carbon precursors together into one ordered 3D crystal structure. MOF precursors not only connect each individual precursor in a controlled manner with defined chemistry, but also possess high surface area capable of accommodating increased active sites and benefiting to mass transfer. In addition, the structure-defined precursors minimize the generation of inactive species during heat treatment, reducing tedious post-treatment synthesis steps to remove inactive species, thus lowering the cost of PGM-free catalysts. In 2010, Liu et al. at Argonne National Laboratory pioneered MOF-derived PGM catalyst by introducing a cobalt zeolitic imidazolate framework-derived carbon catalyst for the ORR in acid, showing promising performance with low cost precursors and a simple synthesis procedure to fulfill the requirement of ORR catalysts 
$[55,70]$. This effort initiated the exploration of using MOF to prepare PGM-free ORR catalysts. Most recently, Fe/MOF hybrid catalysts have shown ORR activity approaching to a Pt cathode in fuel cells [71-73]. These unprecedented achievements encourage scientists to develop PGM-free catalysts by using the well-defined MOF precursors to engineer their nanostructures and morphologies with increased density of active sites and strengthened bonding structures. More importantly, the structurally well-defined and homogeneous MOF model catalysts are ideal fundamental platforms to probe active sites and elucidate bonding structures among each element, which remains elusive for decades in the field. In this review, we discuss recent development of MOF-derived ORR catalysts with emphasis on elucidation of the rules used for engineering catalyst nanostructure via various precursors and synthetic approaches.

\section{General approach to design MOF-derived catalysts}

The general requirements for highly active ORR catalysts are (1) intrinsically high reactivity of active sites, (2) large density of active sites, (3) efficient transfer of electrons and reagents, (4) good durability in fuel cell operation [42]. Thus, the MOF precursors need to be converted into highly porous and graphitized carbon with large amounts of uniformly distributed highly active catalytic sites. Thus, rational design of MOFs with various ligands and metals (secondary building units), as well as proper interactions with other precursors in appropriate synthetic ways are essential to achieve highly active ORR catalysts. In this section, we will summarize general principles to design and synthesize ORR catalysts obtained from MOF precursors by considering the metals and ligands precursors as well as synthetic approaches.

\subsection{MOF precursors}


Since the most promising M-N-C ORR catalysts were prepared via high temperature treatments, MOF-based materials, simultaneously containing carbon, nitrogen, and metal, are recognized as ideal precursors to produce carbon composite catalysts. Due to the complex reaction systems in high temperature treatment, chemical and physical properties of MOF precursors plays a crucial role in generating highly active ORR catalysts. Here we classify MOF-based precursors into two categories: MOFs crystal precursors and MOF composite precursors. MOF crystals refer to the sole presence of MOF crystals without any other additional components. All precursors are integrated into the crystal framework matrix for further pyrolysis. This requires well-controlled synthesis to produce MOF crystals with heterogeneity. MOF composites precursors are defined as MOF crystals mixed with other additional molecules as precursors. We divide MOF composite precursors further into two groups: MOF hybrid composites and templated-MOF composites. Among MOF hybrid composites, MOFs act similarly to carbon supports in traditional catalyst synthesis, offering their surface and pores for metal and nitrogen precursors to absorb and form active sites; however, unlike traditional carbon supports, MOF can enable the synergistic incorporation of nitrogen and metals into carbon matrix during carbonization because of its well-defined 3D network structure. In addition, the high volume of micropores in MOFs is favorable to increasing density of active sites [46]. In templated-MOF composites, MOFs grow in situ on a template such as graphene or carbon nanotubes [74, 75], assembling into a unique superstructure of MOFs, thus increasing the effective surface area and accessibility of active sites for the catalyst. MOF composites provide more opportunities to combine various synthesis chemistry and fabrication approaches to maximize the activity of ORR catalysts, while individual MOF crystals are good model candidates to study the structure-activity correlations of ORR catalysts due to their well-defined and ordered structures. The composition and 
morphology of catalysts can be easily linked with their precursors such as particle size, porous structure and metal contents in MOF crystals. It has been discovered that the crystal particle size and shapes of MOF crystal could be retained after the thermal conversion. The microporous structure of MOFs crystals can be also largely preserved after carbonization if the ligands are relatively rigid. The metal contents of the catalysts can be readily tuned by chemically doping metals into MOFs precursors. Thus, these feasibilities allow use to engineer catalyst morphologies and nanostructures in order to optimize the density of active sties and mass transfer during the ORR, which is the most attractive features to use MOFs as precursors.

\subsection{Metal and ligand precursors}

Metal ions, as knots in 3D hydro-carbon networks, are required to construct MOF crystals, thus the introduction of metal elements is unavoidable for MOF-based catalysts. A wide variety of metals can be used to construct MOFs. $\mathrm{Al}, \mathrm{Mg}, \mathrm{Mn}, \mathrm{Fe}, \mathrm{Co}, \mathrm{Ni}, \mathrm{Cu}$, and $\mathrm{Zn}$ have been used to synthesize MOFs precursors to produce ORR active catalysts for alkaline medium. [76, 77] Noticeably, $\mathrm{Al}, \mathrm{Mg}$, and $\mathrm{Zn}$ are only generally used as structural ions and not facilitate the ORR activity enhancement for the resulting nitrogen-doped carbon. However, they are able to generate high surface area during the high temperature treatments, because they can be easily removed during high temperature treatment or acid-leaching treatment leaving for voids in catalysts. Therefore, in such an approach, these metal ions only play a role as the skeleton for MOF precursors, not involved in active site formation, which is recognized as sacrifice templates. On the other hand, only Fe and Co-containing MOFs derived catalysts currently exhibited enhanced ORR activity, likely due to the formation of active $\mathrm{FeN}_{\mathrm{x}}$ and $\mathrm{CoN}_{\mathrm{x}}$ sites $[56,78,79]$. Fecontaining catalysts have been recognized as the one with the highest ORR activity in more challenging acidic media. However, Fe could cause the stability issue of fuel cells owing to the 
generation of well-known Fenton agents that can severely damage the proton exchange membrane or ionomer in cathodes [49]. Recent studies indicated that iron-free catalysts also suffer from poor stability [80]. Thus, in addition to the iron-related reasons, the degradation of the catalysts could be also attributed to the nitrogen oxidation, carbon corrosion, and possible water flooding in the micropores of cathodes. Despite of the debates on iron issues for ORR catalysts, Co-based ORR catalysts have also been explored as alternatives in parallel. In addition, $\mathrm{Ni}$ - and $\mathrm{Cu}$-derived carbon catalysts exhibited good ORR activity in alkaline electrolytes [76, 77], however, their poor intrinsic activity for ORR in acidic electrolytes limits their potential application in acidic Nafion ${ }^{\circledR}$-based PEM fuel cells. Notably, Mn-based catalyst is able to generate high activity in acids for the ORR [81], however MOF-derived Mn catalysts is rarely reported. Thus, we will mainly focus on Fe- and Co-based MOF-derived ORR catalysts in this review.

The variety of available ligands is attractive for the design and synthesis of different MOFs. The change in ligands with the same metals significantly affects the topology and pore structure of MOFs [82, 83]. Ligands are used as both carbon and nitrogen precursors for M-N-C catalysts. To introduce as many nitrogen doping into carbon as possible to boost ORR activity, ligands with aromatic nitrogen and other high nitrogen content (e.g., imidazolate, pyrazolate, triazolate, and tetrazolate) are highly favorable for the formation of $\mathrm{N}$-doped carbon or $\mathrm{M}-\mathrm{N}-\mathrm{C}$ carbon catalysts [84]. In addition, they also act as a skeleton for controlling the final nanostructure and morphologies of final carbon catalysts, because the resulting carbon structure is obtained by the carbonization of these ligands. Thus careful design and selection of ligands are crucial for achieving highly active ORR catalysts with optimal porosity and morphologies. Among studied MOFs precursor, the zeolitic imidazolate frameworks (ZIFs) derived ORR catalysts has been 
widely investigated and reported with most promising ORR performance. ZIFs are built into zeolite-like three-dimensional crystal structures by repeating coordination between tetrahedral metal ions (e.g., Zn, Co) and imidazolate compounds [85]. Several reasons could be possibly explained that ZIFs are recognized as the most desirable precursors. Asides from the high surface area, versatile topology, ordered and microprous structures, their excellent chemical and thermal stability makes them effective to be catalyst precursors [86]. The rigorous crystal shapes with micropores could be mostly retained after pyrolysis, offering a great opportunity to control the structure and morphology of the ORR catalysts. In addition, imidazolate ligands contain aromatic nitrogen with high nitrogen content, which is beneficial to the formation of nitrogen doped carbon during the carbonization [84]. Compared to the other MOFs with metal-oxygen chelating, the metal-nitrogen coordination in ZIFs, such as $\mathrm{Fe}-\mathrm{N}_{4}$ or $\mathrm{Co}-\mathrm{N}_{4}$, is possibly favorable for the formation of $\mathrm{MN}_{\mathrm{x}}$ active sites during high temperature treatments [87].

\subsection{General synthetic approach}

General synthesis procedures of M-N-C catalysts contain two stages: precursor synthesis and active sites formation during high temperature treatments. The features of MOF precursors such as topology, size, and micropore volume of the MOF crystals are greatly related to the morphology, surface area and activity of the final carbon composite catalyst. For instance, ORR catalysts derived from smaller Co-containing ZIF-67 crystals display more porous feature with improved half-wave potential according to the measured ORR polarization plots, likely due to the enhancement of mass transfer and active site accessibility [88]. Therefore, synthetic approaches for specific MOFs should be properly designed to obtain MOF crystal precursors with optimal properties. During high temperature treatment, both inert and reactive gas such as $\mathrm{NH}_{3}$ are employed to enhance catalyst performance. For MOF composite precursors especially, 
various techniques such as electrospin and guest-induced control into pores of MOFs were employed to combine MOF crystals with other precursors. The currently synthesized MOFderived catalysts and their corresponding ORR activity in terms of onset and half-wave potentials determined by using rotating ring-disk electrode (RRDE) are summarized in alkaline electrolytes (Table 1) and acid electrolytes (Table 2), respectively.

Table 1. Summary of synthesis and ORR activity MOF-derived catalysts in alkaline electrolytes.

\begin{tabular}{|c|c|c|c|c|c|c|c|c|c|c|}
\hline Metals & MOFs & $\begin{array}{c}\text { Other } \\
\text { precursor } \\
\text { s }\end{array}$ & $\begin{array}{c}1^{\text {st }} \\
\text { heat } \\
\text { treatm } \\
\text { ent } \\
\end{array}$ & $\begin{array}{c}\text { Acid- } \\
\text { leaching }\end{array}$ & $\begin{array}{l}2^{\text {nd }} \text { heat } \\
\text { treatment }\end{array}$ & $\begin{array}{c}\text { Electrolytes } \\
\text { and rpm }\end{array}$ & $\begin{array}{c}\text { Onset } \\
\text { potentials }\end{array}$ & $\begin{array}{c}\text { Half } \\
\text { wave } \\
\text { potentia } \\
\text { ls }\end{array}$ & $\begin{array}{c}\text { Fuel } \\
\text { cell test }\end{array}$ & Ref \\
\hline $\mathrm{Zn}$ & ZIF-8 & - & $\begin{array}{c}1000 \\
{ }^{\circ} \mathrm{C}, \mathrm{N}_{2}\end{array}$ & - & - & $\begin{array}{c}0.1 \mathrm{M} \\
\mathrm{KOH}, 1600 \\
\mathrm{rpm} \\
\end{array}$ & $\begin{array}{c}-0.02 \mathrm{~V} \text { (vs. } \\
\mathrm{Ag} / \mathrm{AgCl})\end{array}$ & $-0.20 \mathrm{~V}$ & - & [89] \\
\hline $\mathrm{Zn}$ & ZIF-8 & $\begin{array}{l}\text { Graphen } \\
\text { e oxide } \\
\text { and } \\
\text { poly(vin } \\
\text { yl } \\
\text { pyrrolido } \\
\text { ne) }\end{array}$ & $\begin{array}{c}800 \\
{ }^{\circ} \mathrm{C}, \mathrm{Ar}\end{array}$ & Yes & - & $\begin{array}{c}0.1 \mathrm{M} \\
\mathrm{KOH}, 1600 \\
\text { rpm }\end{array}$ & $\begin{array}{c}-0.02 \mathrm{~V} \text { (vs. } \\
\mathrm{Ag} / \mathrm{AgCl})\end{array}$ & $-0.12 \mathrm{~V}$ & Yes & [74] \\
\hline $\mathrm{Zn}$ & ZIF-8 & $\begin{array}{c}\text { Carbon } \\
\text { nanotube }\end{array}$ & $\begin{array}{c}1000 \\
{ }^{\circ} \mathrm{C}, \mathrm{Ar}\end{array}$ & Yes & - & $\begin{array}{c}0.1 \mathrm{M} \\
\mathrm{KOH}, 1600 \\
\mathrm{rpm}\end{array}$ & $\begin{array}{l}1.03 \mathrm{~V} \text { (vs } \\
\text { RHE) }\end{array}$ & $0.88 \mathrm{~V}$ & - & [75] \\
\hline $\mathrm{Zn}$ & ZIF-8 & $\begin{array}{l}\text { Carbon } \\
\text { nanotube } \\
\text { and } \\
\text { polydopa } \\
\text { mine }\end{array}$ & $\begin{array}{c}900 \\
{ }^{\circ} \mathrm{C}, \mathrm{Ar}\end{array}$ & Yes & - & $\begin{array}{c}0.1 \mathrm{M} \\
\mathrm{KOH}, 1600 \\
\mathrm{rpm}\end{array}$ & $\begin{array}{c}-0.19 \mathrm{~V} \mathrm{(vs.} \\
\mathrm{Ag} / \mathrm{AgCl})\end{array}$ & $-0.08 \mathrm{~V}$ & - & [90] \\
\hline $\mathrm{Zn}$ & ZIF-8 & $\begin{array}{c}\text { Dopamin } \\
\mathrm{e}\end{array}$ & $\begin{array}{l}800 \\
{ }^{\circ} \mathrm{C}, \\
\mathrm{Ar}\end{array}$ & Yes & - & $\begin{array}{c}0.1 \mathrm{M} \\
\mathrm{KOH}, 1600 \\
\mathrm{rpm}\end{array}$ & $\begin{array}{c}0.88 \mathrm{~V} \text { (vs } \\
\text { RHE) }\end{array}$ & $0.81 \mathrm{~V}$ & - & [91] \\
\hline $\mathrm{Zn}$ & ZIF-8 & $\begin{array}{l}\text { Mesopor } \\
\text { ous } \mathrm{SiO}_{2}\end{array}$ & $\begin{array}{l}900 \\
{ }^{\circ} \mathrm{C}, \\
\mathrm{N}_{2} \\
\end{array}$ & Yes & - & $\begin{array}{c}0.1 \mathrm{M} \\
\mathrm{KOH}, 1600 \\
\mathrm{rpm}\end{array}$ & $-0.08 \mathrm{~V}$ & $-0.15 \mathrm{~V}$ & - & [92] \\
\hline $\mathrm{Zn}$ & ZIF-8 & $\begin{array}{c}\text { Telluriu } \\
\text { m } \\
\text { nanowire } \\
\mathrm{s} \\
\end{array}$ & $\begin{array}{l}1000 \\
{ }^{\circ} \mathrm{C}, \mathrm{Ar}\end{array}$ & - & - & $\begin{array}{c}0.1 \mathrm{M} \\
\mathrm{KOH}, 1600 \\
\mathrm{rpm}\end{array}$ & $\begin{array}{c}-0.14 \mathrm{~V} \text { (vs. } \\
\mathrm{Ag} / \mathrm{AgCl} \text { ) }\end{array}$ & $-0.23 \mathrm{~V}$ & - & [93] \\
\hline $\mathrm{Zn}$ & ZIF-8 & $\begin{array}{c}\text { CdTe } \\
\text { nanowire } \\
\mathrm{s} \\
\end{array}$ & $\begin{array}{c}1000 \\
{ }^{\circ} \mathrm{C} \\
\mathrm{N}_{2} \\
\end{array}$ & - & - & $\begin{array}{c}0.1 \mathrm{M} \\
\mathrm{KOH}, \\
1600 \mathrm{rpm} \\
\end{array}$ & $\begin{array}{l}-0.06 \text { (vs. } \\
\mathrm{Ag} / \mathrm{AgCl} \text { ) }\end{array}$ & $-0.17 \mathrm{~V}$ & - & [94] \\
\hline $\mathrm{Zn}$ & MOF-5 & $\begin{array}{c}\text { Melamin } \\
\mathrm{e}\end{array}$ & $\begin{array}{c}1000 \\
{ }^{\circ} \mathrm{C}, \mathrm{Ar}\end{array}$ & - & $\begin{array}{l}550^{\circ} \mathrm{C} \\
900^{\circ} \mathrm{C}\end{array}$ & $\begin{array}{c}0.1 \mathrm{M} \\
\mathrm{KOH}, 1600 \\
\mathrm{rpm}\end{array}$ & $\begin{array}{c}0.03 \mathrm{~V} \text { (vs. } \\
\mathrm{Hg} / \mathrm{Hgo})\end{array}$ & $-0.15 \mathrm{~V}$ & - & [95] \\
\hline $\mathrm{Zn}$ & MOF-5 & Urea and & 900 & Yes & - & & $-0.02 \mathrm{~V}$ (vs. & $-0.15 \mathrm{~V}$ & - & [84] \\
\hline
\end{tabular}




\begin{tabular}{|c|c|c|c|c|c|c|c|c|c|c|}
\hline & & $\begin{array}{l}\text { Dimethyl } \\
\text { sulfoxide }\end{array}$ & ${ }^{\circ} \mathrm{C}, \mathrm{N}_{2}$ & & & $\begin{array}{c}0.1 \mathrm{M} \\
\mathrm{KOH}, 1600 \\
\mathrm{rpm}\end{array}$ & $\mathrm{Ag} / \mathrm{AgCl})$ & & & \\
\hline $\mathrm{Zn}$ & MOF-5 & $\begin{array}{c}\text { DCDA } \\
\text { (dicyandi } \\
\text { amid), } \\
\text { TPP(triar } \\
\text { ylphosph } \\
\text { ine), } \\
\text { DMSO }\end{array}$ & $\begin{array}{c}900 \\
{ }^{\circ} \mathrm{C}, \mathrm{N}_{2}\end{array}$ & Yes & - & $\begin{array}{c}0.1 \mathrm{M} \\
\mathrm{KOH}, 1600 \\
\mathrm{rpm}\end{array}$ & $\begin{array}{c}-0.03 \mathrm{~V}(\mathrm{vs} . \\
\mathrm{Ag} / \mathrm{AgCl})\end{array}$ & $-0.17 \mathrm{~V}$ & - & [96] \\
\hline $\mathrm{Al}$ & $\begin{array}{l}\text { Amino- } \\
\text { MIL- } \\
53(\mathrm{Al})\end{array}$ & - & $\begin{array}{c}1000 \\
{ }^{\circ} \mathrm{C}, \mathrm{N}_{2}\end{array}$ & Yes & - & $\begin{array}{c}0.1 \mathrm{M} \\
\mathrm{KOH}, 1600 \\
\text { rpm }\end{array}$ & $\begin{array}{c}-0.13 \mathrm{~V} \text { (vs. } \\
\mathrm{Ag} / \mathrm{AgCl})\end{array}$ & $-0.22 \mathrm{~V}$ & - & [97] \\
\hline $\mathrm{Co}$ & ZIF-67 & - & $\begin{array}{l}900 \\
{ }^{\circ} \mathrm{C}, \\
\mathrm{Ar}\end{array}$ & Yes & $\begin{array}{c}900{ }^{\circ} \mathrm{C} \\
\mathrm{Ar}\end{array}$ & $\begin{array}{c}0.1 \mathrm{M} \\
\mathrm{KOH}, 1600 \\
\mathrm{rpm}\end{array}$ & $\begin{array}{l}0.98 \mathrm{~V} \text { (vs } \\
\text { RHE) }\end{array}$ & $0.86 \mathrm{~V}$ & - & \\
\hline $\mathrm{Co}, \mathrm{Zn}$ & $\begin{array}{c}\text { ZIF- } \\
67 / \mathrm{ZIF}-8\end{array}$ & $\begin{array}{c}\text { Tripenyl } \\
\text { phosphin } \\
\mathrm{e} \\
\end{array}$ & $\begin{array}{c}900 \\
{ }^{\circ} \mathrm{C}, \mathrm{N}_{2} \\
\end{array}$ & Yes & - & $\begin{array}{c}0.1 \mathrm{M} \\
\mathrm{KOH}, 1600 \\
\mathrm{rpm}\end{array}$ & $\begin{array}{c}-0.04 \mathrm{~V} \text { (vs. } \\
\mathrm{Ag} / \mathrm{AgCl})\end{array}$ & $-0.12 \mathrm{~V}$ & - & {$[9$} \\
\hline $\mathrm{Co}, \mathrm{Zn}$ & $\begin{array}{c}\text { ZIF- } \\
67 / Z I F-8\end{array}$ & - & $\begin{array}{c}900 \\
{ }^{\circ} \mathrm{C}, \mathrm{Ar}\end{array}$ & - & - & $\begin{array}{c}0.1 \mathrm{M} \\
\mathrm{KOH}, 1600 \\
\mathrm{rpm}\end{array}$ & $\begin{array}{c}0.98 \mathrm{~V} \text { (vs } \\
\text { RHE) }\end{array}$ & $0.87 \mathrm{~V}$ & - & [99] \\
\hline $\mathrm{Co}, \mathrm{Zn}$ & $\begin{array}{c}\text { ZIF- } \\
67 / \mathrm{ZIF}-8\end{array}$ & - & $\begin{array}{c}1000 \\
{ }^{\circ} \mathrm{C}, \mathrm{Ar}\end{array}$ & - & - & $\begin{array}{c}0.1 \mathrm{M} \\
\mathrm{KOH}, 1600 \\
\mathrm{rpm}\end{array}$ & $\begin{array}{c}0.98 \mathrm{~V} \text { (vs } \\
\text { RHE) }\end{array}$ & $0.90 \mathrm{~V}$ & - & {$[100]$} \\
\hline $\mathrm{Co}$ & ZIF-67 & $\begin{array}{c}\text { Thiourea } \\
\text { and } \\
\mathrm{CoCl}_{2} \\
\end{array}$ & $\begin{array}{l}900 \\
{ }^{\circ} \mathrm{C}, \\
\mathrm{N}_{2} \\
\end{array}$ & - & - & $\begin{array}{c}0.1 \mathrm{M} \\
\mathrm{KOH}, 1600 \\
\mathrm{rpm}\end{array}$ & $\begin{array}{c}-0.17 \mathrm{~V}(\mathrm{vs} . \\
\mathrm{Ag} / \mathrm{AgCl})\end{array}$ & $-0.05 \mathrm{~V}$ & - & {$[101]$} \\
\hline $\mathrm{Co}$ & ZIF-67 & $\begin{array}{l}\text { Thioacet } \\
\text { amide }\end{array}$ & $\begin{array}{l}{ }^{6000} \\
{ }^{\circ} \mathrm{C}, \\
\mathrm{N}_{2}\end{array}$ & - & - & $\begin{array}{c}0.1 \mathrm{M} \\
\mathrm{KOH}, 1600 \\
\mathrm{rpm}\end{array}$ & $\begin{array}{c}0.96 \mathrm{~V} \text { (vs } \\
\text { RHE) }\end{array}$ & $0.82 \mathrm{~V}$ & - & {$[102]$} \\
\hline $\mathrm{Co}$ & ZIF-67 & $\begin{array}{l}\text { CoAL- } \\
\text { LDH }\end{array}$ & $\begin{array}{l}{ }^{800} \\
{ }^{\circ} \mathrm{C}, \\
\mathrm{N}_{2}\end{array}$ & Yes & - & $\begin{array}{c}0.1 \mathrm{M} \\
\mathrm{KOH}, 1600 \\
\mathrm{rpm}\end{array}$ & $\begin{array}{l}0.94 \mathrm{~V} \text { (vs } \\
\text { RHE) }\end{array}$ & $0.83 \mathrm{~V}$ & - & [92] \\
\hline Co & ZIF-67 & $\begin{array}{l}\text { CoAL- } \\
\text { LDH }\end{array}$ & $\begin{array}{l}800 \\
{ }^{\circ} \mathrm{C}, \\
\mathrm{N}_{2}\end{array}$ & Yes & - & $\begin{array}{c}0.1 \mathrm{M} \\
\mathrm{KOH}, \\
1600 \mathrm{rpm}\end{array}$ & $\begin{array}{c}0.98 \mathrm{~V} \text { (vs } \\
\text { RHE) }\end{array}$ & $0.85 \mathrm{~V}$ & - & {$[103]$} \\
\hline $\mathrm{Co}$ & CPM-24 & - & $\begin{array}{l}700 \\
{ }^{\circ} \mathrm{C} \\
\mathrm{Ar}\end{array}$ & - & - & $\begin{array}{c}0.1 \mathrm{M} \\
\mathrm{KOH}, 1600 \\
\mathrm{rpm}\end{array}$ & $\begin{array}{c}0.78 \mathrm{~V} \text { (vs } \\
\text { RHE) }\end{array}$ & $0.90 \mathrm{~V}$ & - & {$[104]$} \\
\hline $\mathrm{Co}$ & ZIF-9 & Sulfur & $\begin{array}{l}900 \\
{ }^{\circ} \mathrm{C} \\
\mathrm{N}_{2}\end{array}$ & - & - & $\begin{array}{c}0.1 \mathrm{M} \\
\mathrm{KOH}, 1600 \\
\mathrm{rpm}\end{array}$ & $\begin{array}{c}0.95 \mathrm{~V} \text { (vs } \\
\text { RHE) }\end{array}$ & $0.85 \mathrm{~V}$ & - & [105] \\
\hline $\mathrm{Fe}, \mathrm{Zn}$ & Fe-ZIF-7 & - & $\begin{array}{l}1000 \\
{ }^{\circ} \mathrm{C}, \\
\mathrm{N}_{2}\end{array}$ & Yes & - & $\begin{array}{c}0.1 \mathrm{M} \\
\mathrm{KOH}, 1600 \\
\mathrm{rpm}\end{array}$ & $\begin{array}{c}1.04 \mathrm{~V} \text { (vs } \\
\text { RHE) }\end{array}$ & $0.87 \mathrm{~V}$ & - & [106] \\
\hline $\mathrm{Fe}$ & $\begin{array}{l}\text { IRMOF- } \\
\quad 3\end{array}$ & - & $\begin{array}{l}800 \\
{ }^{\circ} \mathrm{C}, \\
\mathrm{Ar}\end{array}$ & - & - & $\begin{array}{c}0.1 \mathrm{M} \\
\mathrm{KOH}, 1600 \\
\mathrm{rpm}\end{array}$ & $\begin{array}{c}0.93 \mathrm{~V} \text { (vs } \\
\text { RHE) }\end{array}$ & $0.78 \mathrm{~V}$ & - & {$[107]$} \\
\hline $\mathrm{Fe}$ & $\begin{array}{c}\text { MIL- } \\
\text { 88B-NH }\end{array}$ & - & $\begin{array}{l}900 \\
{ }^{\circ} \mathrm{C} \\
\mathrm{Ar}\end{array}$ & - & - & $\begin{array}{c}0.1 \mathrm{M} \\
\mathrm{KOH}, 1600 \\
\mathrm{rpm}\end{array}$ & $\begin{array}{c}1.03 \mathrm{~V} \text { (vs } \\
\text { RHE) }\end{array}$ & $0.92 \mathrm{~V}$ & - & [97] \\
\hline $\mathrm{Fe}, \mathrm{Zn}$ & ZIF-8 & $\begin{array}{c}\text { Iron } \\
\text { acetate(II } \\
\text { ) and } \\
1,10-\end{array}$ & $\begin{array}{l}1050 \\
{ }^{\circ} \mathrm{C} \\
\mathrm{Ar}\end{array}$ & - & $\begin{array}{c}1050{ }^{\circ} \mathrm{C}, \\
\mathrm{NH}_{3}\end{array}$ & $\begin{array}{c}0.1 \mathrm{M} \\
\mathrm{KOH}, 1600 \\
\mathrm{rpm}\end{array}$ & $\begin{array}{c}1.03 \mathrm{~V} \text { (vs } \\
\text { RHE) }\end{array}$ & $\begin{array}{c}\text { b) } 0.87 \\
\mathrm{~V}\end{array}$ & Yes & [108] \\
\hline
\end{tabular}




\begin{tabular}{|c|c|c|c|c|c|c|c|c|c|c|}
\hline & & $\begin{array}{c}\text { phenanth } \\
\text { roline }\end{array}$ & & & & & & & & \\
\hline $\mathrm{Fe}, \mathrm{Zn}$ & ZIF-8 & $\begin{array}{l}\text { Dicyandi } \\
\text { amide }\end{array}$ & $\begin{array}{l}900 \\
{ }^{\circ} \mathrm{C}, \\
\mathrm{N}_{2} \\
\end{array}$ & Yes & $\begin{array}{c}700{ }^{\circ} \mathrm{C}, \\
\mathrm{N}_{2}\end{array}$ & $\begin{array}{c}0.1 \mathrm{M} \\
\mathrm{KOH}, 1600 \\
\mathrm{rpm}\end{array}$ & $\begin{array}{l}-0.23 \mathrm{~V} \text { (vs. } \\
\mathrm{Hg} / \mathrm{Hg}_{2} \mathrm{Cl}_{2} \text { ) }\end{array}$ & $\begin{array}{c}-0.183 \\
\mathrm{~V}\end{array}$ & - & [109] \\
\hline $\mathrm{Fe}$ & MIL-100 & $\begin{array}{c}5- \\
\text { aminotet } \\
\text { razole }\end{array}$ & $\begin{array}{l}800 \\
{ }^{\circ} \mathrm{C}, \\
\mathrm{Ar}\end{array}$ & Yes & - & $\begin{array}{c}0.1 \mathrm{M} \\
\mathrm{KOH}, 1600 \\
\text { rpm }\end{array}$ & $\begin{array}{c}0.92 \mathrm{~V} \text { (vs } \\
\text { RHE) }\end{array}$ & $0.77 \mathrm{~V}$ & - & [110] \\
\hline $\mathrm{Fe}, \mathrm{Co}$ & $\mathrm{Co}(\mathrm{PTP})$ & $\begin{array}{c}\text { Iron } \\
\text { acetate(II } \\
\text { ) and } \\
\text { Dicyandi } \\
\text { amide }\end{array}$ & $\begin{array}{l}1000 \\
{ }^{\circ} \mathrm{C}, \\
\mathrm{N}_{2}\end{array}$ & Yes & $\begin{array}{c}1000{ }^{\circ} \mathrm{C}, \\
\mathrm{N}_{2}\end{array}$ & $\begin{array}{c}0.1 \mathrm{M} \\
\mathrm{KOH}, 900 \\
\mathrm{rpm}\end{array}$ & $\begin{array}{l}\text { b) } 1.02 \mathrm{~V} \\
\text { (vs RHE) }\end{array}$ & b) 0.88 & & [111] \\
\hline
\end{tabular}

Table 2. Summary of synthesis and ORR activity of MOF-derived catalysts.in acid electrolytes

\begin{tabular}{|c|c|c|c|c|c|c|c|c|c|c|}
\hline Metals & MOFs & $\begin{array}{c}\text { Other } \\
\text { precursors }\end{array}$ & $\begin{array}{l}1^{\text {st }} \text { heat } \\
\text { treatment }\end{array}$ & $\begin{array}{c}\text { Acid- } \\
\text { leaching }\end{array}$ & $\begin{array}{l}2^{\text {nd }} \text { heat } \\
\text { treatment }\end{array}$ & $\begin{array}{l}\text { Electrolyt } \\
\text { es and } \\
\text { rpm }\end{array}$ & $\begin{array}{c}\text { Onset } \\
\text { potentials }\end{array}$ & $\begin{array}{c}\text { Half } \\
\text { wave } \\
\text { potenti } \\
\text { als } \\
\end{array}$ & $\begin{array}{l}\text { Fuel } \\
\text { cell } \\
\text { test }\end{array}$ & Ref \\
\hline $\mathrm{Co}$ & CoIM & - & $\begin{array}{c}750^{\circ} \mathrm{C} \\
\mathrm{Ar}\end{array}$ & Yes & - & $\begin{array}{c}0.1 \mathrm{M} \\
\mathrm{HClO}_{4} \\
1600 \mathrm{rpm} \\
\end{array}$ & $\begin{array}{c}0.83 \mathrm{~V} \text { (vs } \\
\text { RHE) }\end{array}$ & $0.68 \mathrm{~V}$ & - & [87] \\
\hline $\mathrm{Co}$ & ZIF-67 & - & $\begin{array}{c}750{ }^{\circ} \mathrm{C} \\
\mathrm{Ar}\end{array}$ & - & - & $\begin{array}{c}0.1 \mathrm{M} \\
\mathrm{HClO}_{4}, \\
1600 \mathrm{rpm}\end{array}$ & $\begin{array}{c}0.86 \mathrm{~V} \text { (vs } \\
\text { RHE) }\end{array}$ & $0.71 \mathrm{~V}$ & - & [88] \\
\hline $\mathrm{Co}$ & ZIF-67 & - & $\begin{array}{c}900{ }^{\circ} \mathrm{C} \\
\mathrm{Ar}\end{array}$ & Yes & $\begin{array}{c}900{ }^{\circ} \mathrm{C} \\
\mathrm{Ar}\end{array}$ & $\begin{array}{c}0.5 \mathrm{M} \\
\mathrm{H}_{2} \mathrm{SO}_{4} \\
900 \mathrm{rpm}\end{array}$ & $\begin{array}{l}0.85 \mathrm{~V} \text { (vs } \\
\text { RHE) }\end{array}$ & $0.71 \mathrm{~V}$ & - & {$[84]$} \\
\hline $\mathrm{Co}, \mathrm{Zn}$ & $\begin{array}{c}\text { ZIF- } \\
67 / Z I F-8\end{array}$ & - & $\begin{array}{c}1000^{\circ} \mathrm{C} \\
\mathrm{Ar}\end{array}$ & Yes & $\begin{array}{c}950{ }^{\circ} \mathrm{C} \\
\mathrm{NH}_{3}\end{array}$ & $\begin{array}{c}0.1 \mathrm{M} \\
\mathrm{HClO}_{4}, \\
1600 \mathrm{rpm}\end{array}$ & $\begin{array}{c}0.93 \mathrm{~V} \text { (vs } \\
\text { RHE) }\end{array}$ & $0.76 \mathrm{~V}$ & Yes & [112] \\
\hline $\mathrm{Fe}, \mathrm{Zn}$ & $\mathrm{Fe}-\mathrm{ZIF}-8$ & - & $\begin{array}{c}1000^{\circ} \mathrm{C} \\
\mathrm{Ar}\end{array}$ & - & - & $\begin{array}{c}0.1 \mathrm{M} \\
\mathrm{HClO}_{4}, \\
1600 \mathrm{rpm} \\
\end{array}$ & $\begin{array}{c}0.95 \mathrm{~V} \text { (vs } \\
\text { RHE) }\end{array}$ & $0.82 \mathrm{~V}$ & - & [113] \\
\hline $\mathrm{Fe}, \mathrm{Zn}$ & $\mathrm{Fe}-\mathrm{ZIF}-7$ & - & $\begin{array}{c}1000{ }^{\circ} \mathrm{C} \\
\mathrm{N}_{2}\end{array}$ & Yes & - & $\begin{array}{c}0.1 \mathrm{M} \\
\mathrm{HClO}_{4}, \\
1600 \mathrm{rpm} \\
\end{array}$ & $\begin{array}{l}0.90 \mathrm{~V} \text { (vs } \\
\text { RHE) }\end{array}$ & $0.78 \mathrm{~V}$ & - & [106] \\
\hline $\mathrm{Fe}, \mathrm{Zn}$ & ZIF-8 & $\begin{array}{c}\text { Furfuryl } \\
\text { alcohol }\end{array}$ & $\begin{array}{c}1050^{\circ} \mathrm{C} \\
\mathrm{Ar}\end{array}$ & - & $\begin{array}{c}950^{\circ} \mathrm{C} \\
\mathrm{NH}_{3}\end{array}$ & $\begin{array}{c}0.1 \mathrm{M} \\
\mathrm{H}_{2} \mathrm{SO}_{4}, \\
1600 \mathrm{rpm}\end{array}$ & $\begin{array}{c}0.93 \mathrm{~V} \text { (vs } \\
\text { RHE) }\end{array}$ & $0.80 \mathrm{~V}$ & Yes & [114] \\
\hline $\mathrm{Fe}, \mathrm{Zn}$ & ZIF-8 & $\begin{array}{c}\mathrm{Fe}(\mathrm{II}) \\
\text { acetate } \\
\text { and } 1,10- \\
\text { phenanthr } \\
\text { oline }\end{array}$ & $\begin{array}{c}1050^{\circ} \mathrm{C} \\
\mathrm{Ar}\end{array}$ & Yes & $\begin{array}{c}950^{\circ} \mathrm{C} \\
\mathrm{NH}_{3}\end{array}$ & $\begin{array}{c}0.1 \mathrm{M} \\
\mathrm{H}_{2} \mathrm{SO}_{4}, \\
1600 \mathrm{rpm}\end{array}$ & $\begin{array}{l}0.98 \mathrm{~V} \text { (vs } \\
\text { RHE) }\end{array}$ & $0.88 \mathrm{~V}$ & Yes & [71] \\
\hline $\mathrm{Fe}, \mathrm{Zn}$ & ZIF-8 & $\begin{array}{c}\text { Iron } \\
\text { acetate(II) } \\
\text { and } 1,10- \\
\text { phenanthr }\end{array}$ & $\begin{array}{c}1050^{\circ} \mathrm{C} \\
\mathrm{Ar}\end{array}$ & - & $\begin{array}{c}1050{ }^{\circ} \mathrm{C} \\
\mathrm{NH}_{3}\end{array}$ & $\begin{array}{c}0.1 \mathrm{M} \\
\mathrm{HClO}_{4}, \\
1600 \mathrm{rpm}\end{array}$ & $\begin{array}{c}0.93 \mathrm{~V} \text { (vs } \\
\text { RHE) }\end{array}$ & $0.78 \mathrm{~V}$ & Yes & [108] \\
\hline
\end{tabular}




\begin{tabular}{|c|c|c|c|c|c|c|c|c|c|c|}
\hline & & oline & & & & & & & & \\
\hline $\mathrm{Fe}$ & FeIM & - & $\begin{array}{c}800{ }^{\circ} \mathrm{C} \\
\mathrm{Ar}\end{array}$ & Yes & $\begin{array}{c}800^{\circ} \mathrm{C} \\
\mathrm{NH}_{3}\end{array}$ & $\begin{array}{c}0.1 \mathrm{M} \\
\mathrm{HClO}_{4}, \\
1600 \mathrm{rpm}\end{array}$ & $\begin{array}{c}0.86 \mathrm{~V} \text { (vs } \\
\text { RHE) }\end{array}$ & $0.68 \mathrm{~V}$ & - & [115] \\
\hline $\mathrm{Fe}, \mathrm{Zn}$ & ZIF-8 & FeIM & $\begin{array}{c}1050^{\circ} \mathrm{C} \\
\mathrm{Ar}\end{array}$ & - & $\begin{array}{c}950^{\circ} \mathrm{C} \\
\mathrm{NH}_{3}\end{array}$ & $\begin{array}{c}0.1 \mathrm{M} \\
\mathrm{HClO}_{4}, \\
1600 \mathrm{rpm}\end{array}$ & $\begin{array}{c}0.90 \mathrm{~V} \text { (vs } \\
\text { RHE) }\end{array}$ & $0.75 \mathrm{~V}$ & Yes & [115] \\
\hline $\mathrm{Fe}, \mathrm{Zn}$ & ZIF-8 & \multirow{4}{*}{$\begin{array}{l}\text { Tris-1,10- } \\
\text { phenanthr } \\
\text { oline and } \\
\text { iron(II) } \\
\text { perchlorat } \\
\text { e }\end{array}$} & \multirow{4}{*}{$\begin{array}{c}1050^{\circ} \mathrm{C} \\
\mathrm{Ar}\end{array}$} & \multirow{4}{*}{ Yes } & \multirow{4}{*}{$\begin{array}{c}950^{\circ} \mathrm{C} \\
\mathrm{NH}_{3}\end{array}$} & $\begin{array}{c}0.1 \mathrm{M} \\
\mathrm{HClO}_{4} \text {, } \\
1600 \mathrm{rpm}\end{array}$ & $\begin{array}{l}0.90 \mathrm{~V} \text { (vs } \\
\text { RHE) }\end{array}$ & $0.76 \mathrm{~V}$ & Yes & [116] \\
\hline $\mathrm{Fe}, \mathrm{Zn}$ & $\mathrm{Zn}(\mathrm{eIm})_{2}$ & & & & & $\begin{array}{c}0.1 \mathrm{M} \\
\mathrm{HClO}_{4} \text {, } \\
1600 \mathrm{rpm}\end{array}$ & $\begin{array}{c}0.91 \mathrm{~V} \text { (vs } \\
\text { RHE) }\end{array}$ & $0.78 \mathrm{~V}$ & Yes & [116] \\
\hline $\mathrm{Fe}, \mathrm{Zn}$ & $\begin{array}{c}\mathrm{Zn}(4 \mathrm{abI} \\
\mathrm{m})_{2}\end{array}$ & & & & & $\begin{array}{c}0.1 \mathrm{M} \\
\mathrm{HClO}_{4} \text {, } \\
1600 \mathrm{rpm}\end{array}$ & $\begin{array}{c}0.90 \mathrm{~V} \text { (vs } \\
\text { RHE) }\end{array}$ & $0.76 \mathrm{~V}$ & Yes & [116] \\
\hline $\mathrm{Fe}, \mathrm{Zn}$ & $\mathrm{Zn}(\mathrm{Im})_{2}$ & & & & & $\begin{array}{c}0.1 \mathrm{M} \\
\mathrm{HClO}_{4}, \\
1600 \mathrm{rpm}\end{array}$ & $\begin{array}{c}0.88 \mathrm{~V} \text { (vs } \\
\text { RHE) }\end{array}$ & $0.73 \mathrm{~V}$ & Yes & [116] \\
\hline $\mathrm{Fe}, \mathrm{Zn}$ & ZIF-68 & \multirow{3}{*}{$\begin{array}{c}\text { Iron } \\
\text { acetate(II) } \\
\text { and } 1,10- \\
\text { phenanthr } \\
\text { oline }\end{array}$} & \multirow{3}{*}{$\begin{array}{c}900{ }^{\circ} \mathrm{C} \\
\mathrm{N}_{2}\end{array}$} & \multirow{3}{*}{ Yes } & \multirow{3}{*}{ - } & $\begin{array}{c}0.1 \mathrm{M} \\
\mathrm{HClO}_{4} \text {, } \\
1600 \mathrm{rpm}\end{array}$ & $\begin{array}{c}0.70 \mathrm{~V} \text { (vs } \\
\text { RHE) }\end{array}$ & $0.50 \mathrm{~V}$ & - & [117] \\
\hline $\mathrm{Fe}, \mathrm{Zn}$ & ZIF-69 & & & & & $\begin{array}{c}0.1 \mathrm{M} \\
\mathrm{HClO}_{4}, \\
1600 \mathrm{rpm}\end{array}$ & $\begin{array}{c}0.60 \mathrm{~V} \text { (vs } \\
\text { RHE) }\end{array}$ & $0.45 \mathrm{~V}$ & - & [117] \\
\hline $\mathrm{Fe}, \mathrm{Zn}$ & ZIF-70 & & & & & $\begin{array}{c}0.1 \mathrm{M} \\
\mathrm{HClO}_{4} \text {, } \\
1600 \mathrm{rpm}\end{array}$ & $\begin{array}{l}0.80 \mathrm{~V} \text { (vs } \\
\text { RHE) }\end{array}$ & $0.58 \mathrm{~V}$ & - & [117] \\
\hline $\mathrm{Fe}, \mathrm{Zn}$ & MIL-100 & $\begin{array}{c}\text { Iron } \\
\text { acetate(II) } \\
\text { and } \\
\text { Dicyandia } \\
\text { mide } \\
\end{array}$ & $\begin{array}{c}1000{ }^{\circ} \mathrm{C}, \\
\mathrm{N}_{2}\end{array}$ & Yes & $\begin{array}{c}1000{ }^{\circ} \mathrm{C} \\
\mathrm{N}_{2}\end{array}$ & $\begin{array}{c}0.5 \mathrm{M} \\
\mathrm{H}_{2} \mathrm{SO}_{4} \\
900 \mathrm{rpm}\end{array}$ & $\begin{array}{l}0.95 \mathrm{~V} \text { (vs } \\
\text { RHE) }\end{array}$ & $0.78 \mathrm{~V}$ & - & [11] \\
\hline $\mathrm{Fe}, \mathrm{Co}$ & $\mathrm{Co}(\mathrm{PTP})$ & $\begin{array}{c}\text { Iron } \\
\text { acetate(II) } \\
\text { and } \\
\text { Dicyandia } \\
\text { mide }\end{array}$ & $\begin{array}{c}1000^{\circ} \mathrm{C}, \\
\mathrm{N}_{2}\end{array}$ & Yes & $\begin{array}{c}1000^{\circ} \mathrm{C} \\
\mathrm{N}_{2}\end{array}$ & $\begin{array}{c}0.5 \mathrm{M} \\
\mathrm{H}_{2} \mathrm{SO}_{4} \\
900 \mathrm{rpm}\end{array}$ & $\begin{array}{l}0.95 \mathrm{~V} \text { (vs } \\
\text { RHE) }\end{array}$ & $0.79 \mathrm{~V}$ & - & [111] \\
\hline
\end{tabular}

\section{Catalysts derived from MOF crystals}

In principle, MOF crystals, consisting of nitrogen-containing hydrocarbon ligands and transition metals, are desirable precursors for $\mathrm{M}-\mathrm{N}-\mathrm{C}$ or $\mathrm{N}-\mathrm{C}$ catalyst synthesis via a high-temperature carbonization approach. The structure and morphology of the final catalyst are greatly dependent on the features of the MOF precursor itself. This would provide a good opportunity to engineer catalyst in terms of optimal density of active sites, carbon phases, and bonding strictures among 
metal, nitrogen and carbon. Importantly, it allows us to probe the MOF-derived model catalysts and elucidate the nature of active sites.

\subsection{MOF crystal precursors containing single inactive metal ions}

In general, homogenous MOFs crystals are comprised of only one metal and one ligand, which gives it a highly ordered crystal structure. Such well-defined crystal structures of pristine MOF precursors are ideal models to understand how the ORR activity of catalysts relates to the structure of their precursors. In special cases, the metals used for connecting hydro-carbon are inactive for the ORR, such as $\mathrm{Zn}, \mathrm{Al}$, and $\mathrm{Mg}$, which can prepare nitrogen-doped carbon catalyst (N-C). The major driving force of exploring such N-C catalyst is to address the stability issues resulting from intrinsically unstable transition metal in catalysts [118]. However, such N-C catalysts still suffer from poor activity and stability in acidic electrolytes during the ORR, likely due to the oxidation of doped nitrogen and carbon corrosion [26]. One of potential applications of N-C catalysts is for air cathode in alkaline or nonaqueous electrolytes for metal-air batteries, which still attract significant attention in the field [47, 119-123].

Among others, $\mathrm{Zn}^{2+}$ containing MOFs have been paid a lot of attention since $\mathrm{Zn}$ can easily be removed during high temperature treatment due to the comparatively low boiling points of $\mathrm{Zn}$ metals $\left(907{ }^{\circ} \mathrm{C}\right)$. Monodispersed zeolitic imidazolite framework (ZIF)-8 nanocrystals with a size of $60 \mathrm{~nm}$ was able to be synthesized by linking $\mathrm{Zn}^{2+}$ and 2-methylimidazole. They were then carbonized to prepare $\mathrm{N}-\mathrm{C}$ catalysts, resulting in partially graphitic porous carbons with retaining their original rhombic dedocanehedron shapes (Figure 1) [89]. This indicates that the architecture of ZIF-8 is rigid even during high temperature treatments. The effect of heating temperature and time on catalyst activity in $0.1 \mathrm{M} \mathrm{KOH}$ were studied. When increasing the temperature from $700{ }^{\circ} \mathrm{C}$ to $1000{ }^{\circ} \mathrm{C}$ for 10 hours, the degree of graphitization of the catalysts 
was significantly improved, corresponding to the highest BET surface area of $932 \mathrm{~m}^{2} / \mathrm{g}$ and the best ORR activity with an onset potential of $-0.02 \mathrm{~V}(v s . \mathrm{Ag} / \mathrm{AgCl})$ and a half-wave potential of $0.20 \mathrm{~V}$ (vs. $\mathrm{Ag} / \mathrm{AgCl})$ in $0.1 \mathrm{M} \mathrm{NaOH}$ electrolytes. Retention of micropores from ZIF-8 crystals and the effectiveness of removing $\mathrm{Zn}$ during the high temperature treatment are responsible for the large amounts of micropores $\left(0.32 \mathrm{~cm}^{3} / \mathrm{g}\right)$ and meso/macropores $\left(0.67 \mathrm{~cm}^{3} / \mathrm{g}\right)$ in the final catalyst, which are beneficial to the increase of active sites and mass transfer in catalyst layers.

Mg-based MOFs precursors-derived N-C catalysts have been used as a model to study the relations between their nitrogen content and ORR activity [124]. By adjusting $\mathrm{pH}$ with potassium carbonate, the $\mathrm{Mg}^{2+}$ coordination with the quaternary amine groups of nitrilotriacetic acid is able to be tuned by protonating and deprotonating, resulting in the significant change in the nitrogen content after pyrolysis at $900{ }^{\circ} \mathrm{C}$ under argon. Meanwhile, the other important features such as surface area and graphitization were in a much less change after high temperature treatment. As a result, it was found that, at lower nitrogen content $(<3$ at $\%)$, the increasing nitrogen amounts in the final catalysts led to the enhancement in the onset potential and half-wave potential of the catalysts in alkaline medium. 

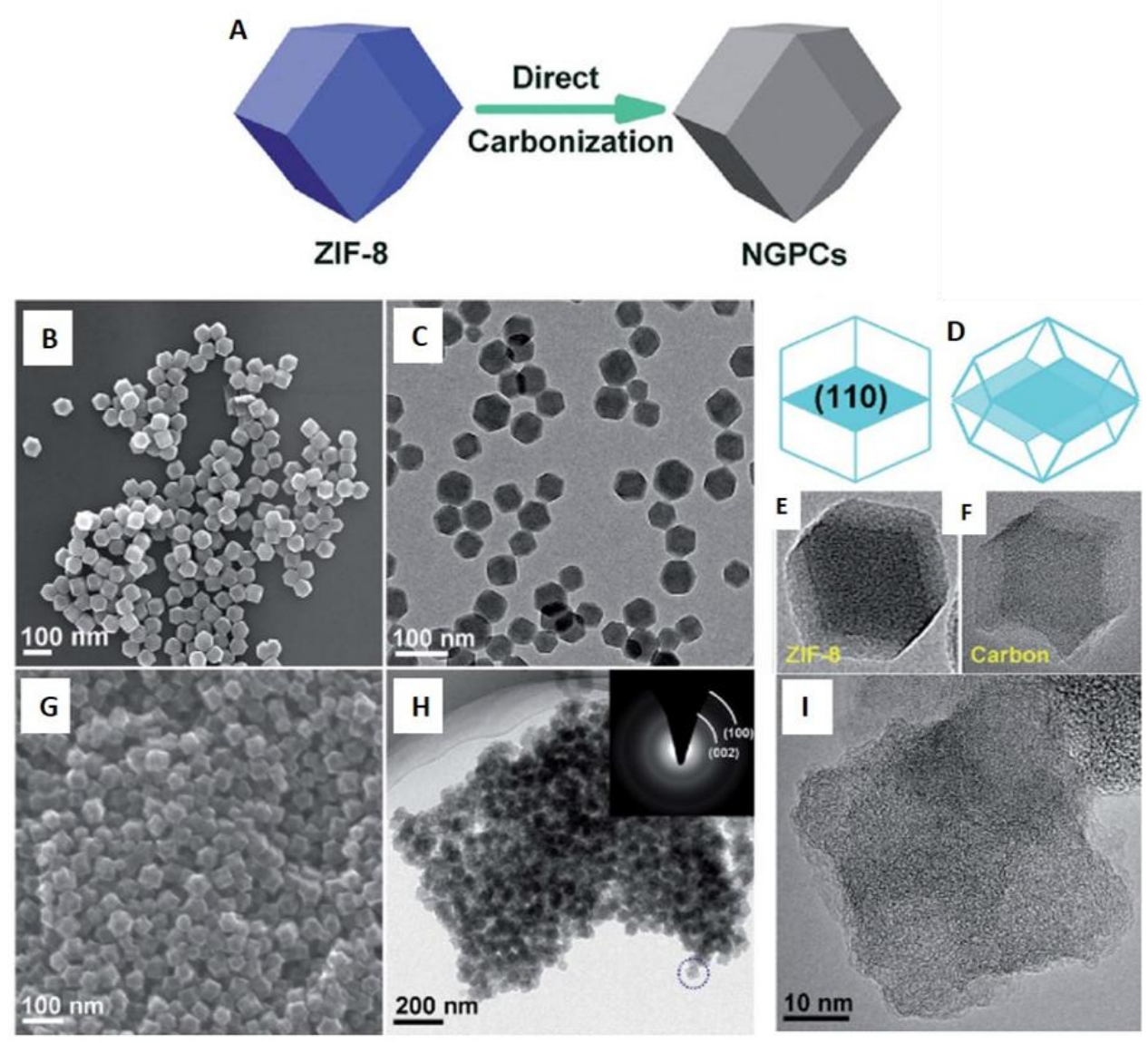

Figure 1. (A) Schematic illustration of direct carbonization of ZIF-8 crystals into nitrogen doped graphitic porous carbons (NGPCs). TEM and SEM images for ZIF-8 crystals (B, C, E) and converted N-C catalysts (F, G, H, and I). (D) Representation of (110) plane of ZIF-8 crystals. Reprinted with permission from Ref. [89] . Copyright 2014, Royal Society of Chemistry.

\subsection{M-N-C catalysts derived from MOFs with single active metals}

Although N-C catalysts exhibited high activity in alkaline electrolyte, their ORR activity in acidic media so far remains insufficient. Transition metal-involved M-N-C catalysts represent the most promising PGM-free catalyst in both alkaline and acidic electrolytes, likely due to the possible metal-nitrogen coordination with much enhanced intrinsic activity. Co-N-C catalysts 
have been extensively developed as PGM-free catalysts since they could avoid using iron that has a potential negative effect on fuel cell performance durability due to the formation of Fenton agent during the ORR. However, the intrinsic activity of $\mathrm{CoN}_{\mathrm{x}}$ active sites are lower than $\mathrm{FeN}_{\mathrm{x}}$ in acid media [125]. An carbon catalyst derived from a cobalt zeolitic imidazolate framework (ZIF67) was first synthesized by Liu's group in 2011 [87]. The carbon/nitrogen precursor imidazole, and the metal precursor, $\mathrm{Co}^{2+}$, are integrated into an ordered crystal structure with well-defined micropores. The Co-containing MOF precursors were further carbonized at $750{ }^{\circ} \mathrm{C}$ followed by acid treatment with diluted $\mathrm{H}_{2} \mathrm{SO}_{4}$ solution. Even that, the residual Co nanoparticles are still embedded in carbon composites. This MOF-derived Co-N-C catalyst showed similar activity to other Co-based catalysts with an onset potential of $0.86 \mathrm{~V} v s$. RHE and a half-wave potential of $0.71 \mathrm{~V}$ in $0.1 \mathrm{M} \mathrm{HClO}_{4}$. The possible $\mathrm{CoN}_{4}$ active sites was identified by using X-ray absorption spectroscopy (XAS). This pioneer work demonstrated that MOF crystals are able to be effective precursors for the synthesis of active M-N-C ORR catalyst via a carbonization process, opening a new synthetic pathway to prepare PGM-free ORR catalysts.

The study of the structure-performance correlation of ORR catalysts derived from Co-based MOFs was reported in 2014 by Wang et al [74]. With the same heating temperature at $900{ }^{\circ} \mathrm{C}$, ZIF-67-derived catalysts contained a much higher nitrogen content (4.0-5.5 at\%) than that of $\mathrm{Co}_{2}(\mathrm{bdc})_{2}(\mathrm{dabco})$-derived carbon $(0.3 \mathrm{at} \%)$ due to the stronger bonds between aromatic nitrogen atoms and carbon atoms than those of aliphatic N. The two Co-based catalysts were composed of Co nanoparticles wrapped into the highly graphitized carbon layers owing to the catalytic effect of Co during pyrolysis. As a comparison, Co-free ZIF-8 crystal-derived catalysts only consisted of amorphous carbon due to the evaporation of $\mathrm{Zn}$ during high temperature treatment. Despite having lower surface area and lower nitrogen content, the ZIF-67-900 catalyst showed much 
higher activities $\left(E_{0}=0.91 \mathrm{~V} ; E_{1 / 2}=0.85 \mathrm{~V}\right.$ in $0.1 \mathrm{M} \mathrm{KOH}$ and $E_{0}=0.85 \mathrm{~V} ; E_{1 / 2}=0.71 \mathrm{~V}$ in $0.1 \mathrm{M}$ $\mathrm{HClO}_{4}$ ) relative to ZIF-8-900, suggesting that Co indeed plays a significant role in enhancing catalyst activity. The activity differences between Co-free ZIF-8-900 and Co-containing ZIF-67900 in alkaline is much less significant than those in acidic electrolyte. This indicates that Co is able to play more important role in acidic media relative to alkaline media. In order to increase the surface area of the ZIF-67-900, a harsh acid-leaching using a hydrothermal treatment was conducted in $10 \mathrm{M} \mathrm{HCl}$ solution at $180{ }^{\circ} \mathrm{C}$ for $24 \mathrm{~h}$ to remove the Co nanoparticles wrapped by carbon, resulting in a decrease in Co from 38.3 at $\%$ to 4.7 at\%. This leaching enhanced the activity of the resulting catalyst in alkaline conditions, but it did not show obvious improvement of ORR activity in acid. This interesting difference may indicate the existence of different active sites in alkaline and acid electrolytes.

The effect of size variation in ZIF-67 crystal precursors on ORR activity has also been explored [88]. The size of ZIF-67 crystals were made in the range of $10 \mu \mathrm{m}$ (bulk crystals) to $300 \mathrm{~nm}$ by varying the solvents and reaction temperature during synthesis (Figure 2). The rhombic dedocanhedron shapes of ZIF-67 crystals were preserved after pyrolysis at $750{ }^{\circ} \mathrm{C}$ under Ar, though their edges became shrunk, and Co nanoparticles around $10 \mathrm{~nm}$ were observed within the shrunken crystals. In addition, after heat treatment, ZIF-67's micropores expanded from around $0.9 \mathrm{~nm}$ with narrow distribution in precursor to small mesopores between $2.0 \mathrm{~nm}$ to 5.0 $\mathrm{nm}$ and large mesopores above $26 \mathrm{~nm}$ with wide distribution in final catalysts. The ZIF-67 crystal with $300 \mathrm{~nm}$ yielded the best ORR activity. With decreasing size of ZIF-67 crystal precursors, the resulting ORR activity of the catalysts were incrementally enhanced in terms of increased diffusion-limiting current and positive half-wave potentials in $0.1 \mathrm{M} \mathrm{HClO}_{4}$. This was explained by an increased density of active sites and their availability within the smaller size 
particles leading to efficient mass and electron transfer. Notably, the inactive metallic cobalt nanoparticles formed within the carbon matrix during high temperature treatment are difficult to be completely removed by subsequent post treatment such as acidic leaching, thereby leading to decreased surface area and mass activity.

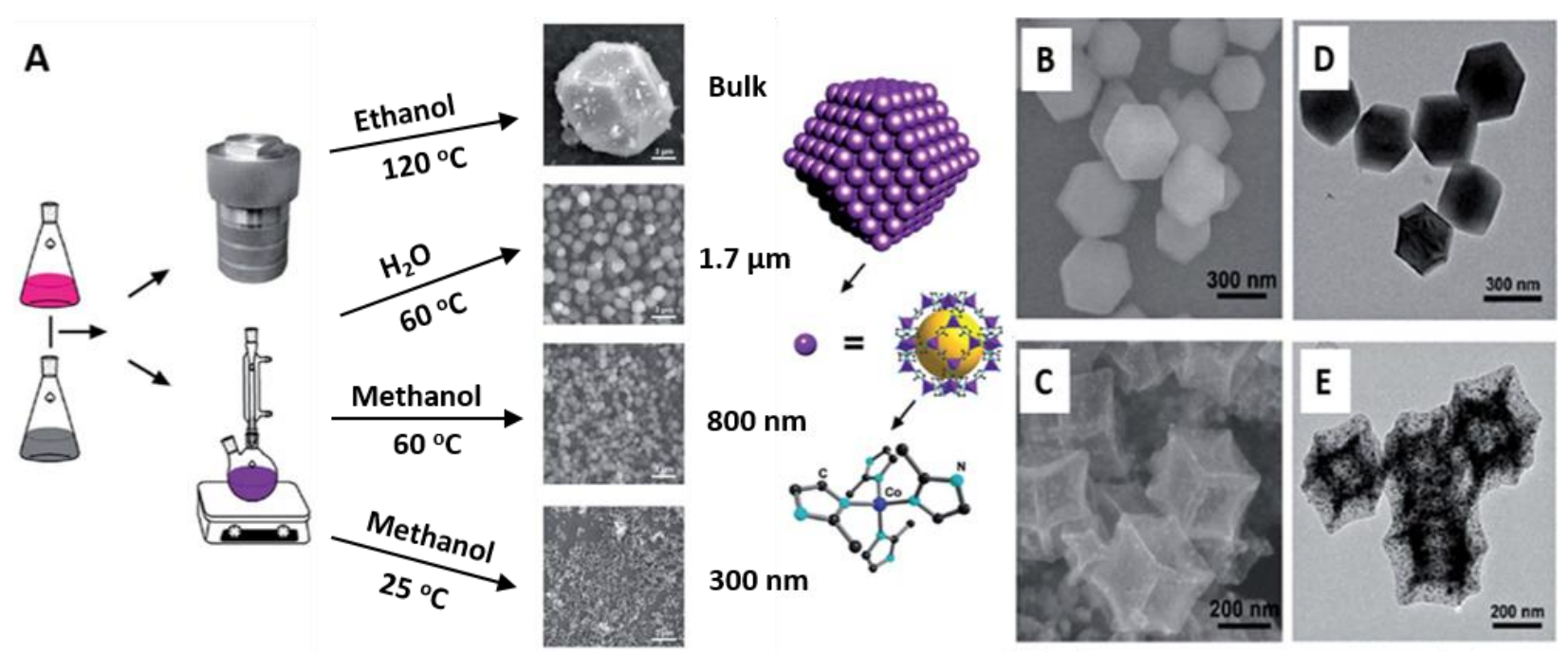

Figure 2. (A) Controlled synthesis of size-dependent ZIF-67 crystals via varying solvents and temperature. Morphologies of (B, D) for $300 \mathrm{~nm}$ ZIF-67 crystals and (C, E) carbonized $300 \mathrm{~nm}$ ZIF-67 crystals. Reprinted with permission from Ref. [88]. Copyright 2014, Royal Society of Chemistry 

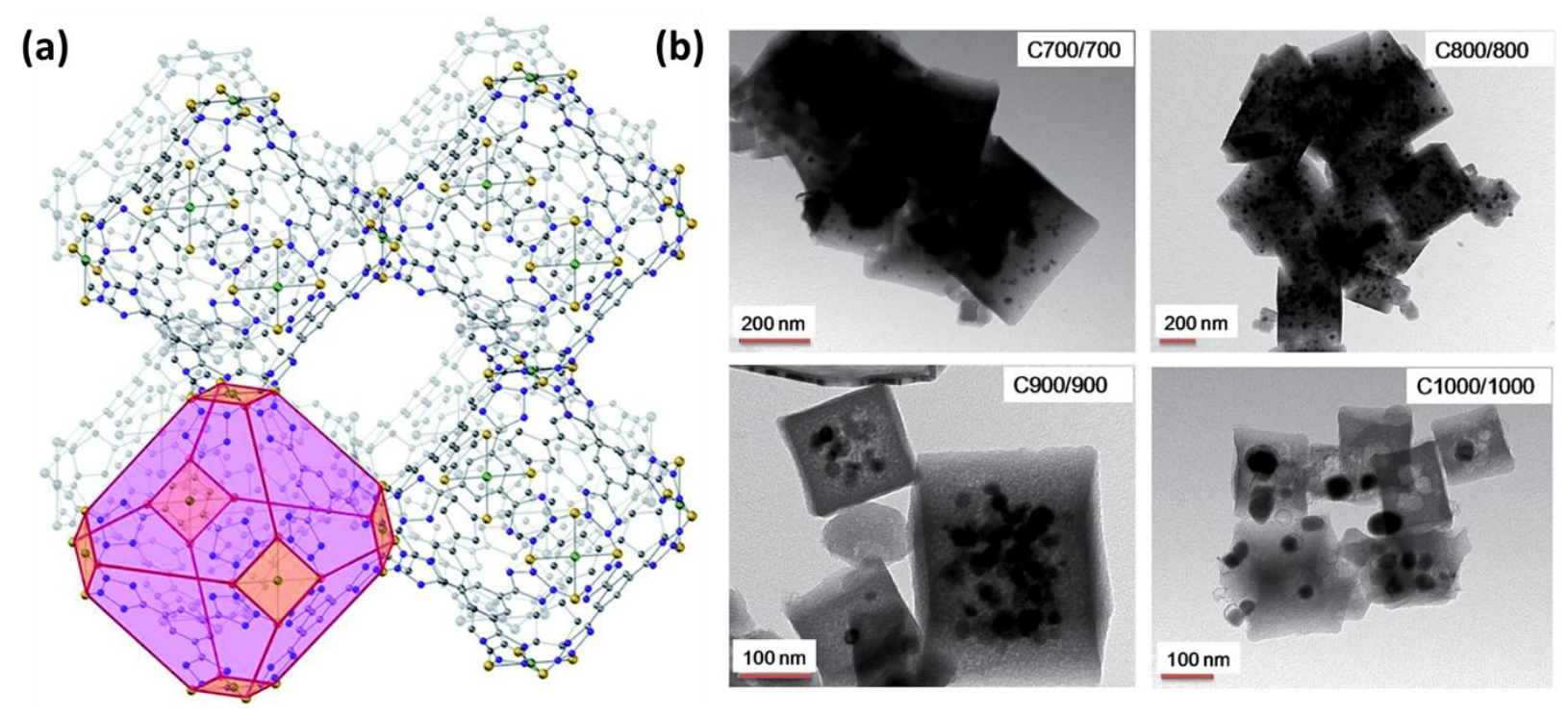

Figure 3. (a) The crystal structure of an Fe-MOF, a cube of eight sodalite-like truncatedoctahedral cages sharing square faces. Fe, yellow; $\mathrm{C}$, gray; $\mathrm{N}$, blue and $\mathrm{Cl}$, green (b) corresponding morphologies of Fe-N-C catalysts obtained at different temperatures. Reprinted with permission from Ref. [126]. Copyright 2014, Royal Society of Chemistry.

Although the cobalt-containing ZIF is the first reported MOF-derived M-N-C ORR catalysts [55], Fe-N-C based catalysts have higher intrinsic ORR activities, especially in acid electrolytes $[50,127]$. Therefore, tremendous efforts have been also made to develop Fe-based MOFs catalysts. As shown in Figure 3, a Fe-N-C catalyst derived from an iron-based sodalite-type MOF (Fe-BTT) crystal was synthesized through a reaction between $\mathrm{FeCl}_{2}$ and $\mathrm{H}_{3} \mathrm{BTT} \cdot 2 \mathrm{HCl}$ $\left(\mathrm{BTT}^{3-}=1,3,5\right.$-benzenetristetrazolate). Through carbonization, acid-leaching and then $\mathrm{NH}_{3}$ heat treatments, the resulting catalysts have cubic morphology containing an abundance of iron carbide particles, probably due to the high concentration of Fe in the MOF precursor [126]. After optimizing the high temperature treatment, the best resulting ORR catalysts exhibited high ORR 
activity in $0.1 \mathrm{M} \mathrm{H}_{2} \mathrm{SO}_{4}$ displaying an onset potentials of $0.91 \mathrm{~V}$ and a half wave potentials of $0.81 \mathrm{~V}$, which was attributed to the presence of large amounts of pyridinic-N and graphitic-N after $\mathrm{NH}_{3}$ heat treatment. In addition, monodisperse spinel-shaped Fe-containing MIL-88B-NH nanocrystals were employed to generate active catalysts via carbonization at $1000{ }^{\circ} \mathrm{C}$ under inert gas, resulting in an onset potential of $1.03 \mathrm{~V}$ and half-wave potential of $0.85 \mathrm{~V}$ in $0.1 \mathrm{M} \mathrm{KOH}$ [97]. Unfortunately, no corresponding activity was studied in acid media.

\subsection{MOF crystals containing binary metal ions}

M-N-C catalysts made from MOF crystals only using sole active transition metals typically contain a large amount of metallic aggregates generated during high temperature synthesis, which results in low surface area and mediocre ORR activity. Bimetallic MOF crystals simultaneously containing both an active metal (e.g., Co and Fe) and an inactive metal (e.g., $\mathrm{Zn}$ and $\mathrm{Al}$ ) would be more desirable to achieve high surface areas and uniform active metal site distribution in the skeleton of MOFs.

\subsubsection{Co/Zn containing MOF crystals-derived catalysts}

Bimetallic Co/Zn MOF crystals Co/Zn-(mIm) 2 (ZIF-67/ZIF-8) usually can be prepared by mixing the $\mathrm{Co}^{2+}$ and $\mathrm{Zn}^{2+}$ together with 2-methylimidazole in methanol to generate bimetallic MOF crystals (Figure 4) [99]. The bimetallic ZIFs were verified by using XRD as well as the $\mathrm{N}_{2}$ isothermal absorption features with ZIF-8 and ZIF-67, uniform rhombic dodecahedron shapes, and well-dispersed $\mathrm{Co}$ and $\mathrm{Zn}$ elements in 3D frameworks. The rationale of this design is that, during high temperature treatments, ZIF-8 $\left(\mathrm{Zn}(\mathrm{mIm})_{2}\right)$ can yield high surface area nitrogendoped carbon, while ZIF-67 $\left(\mathrm{Co}(\mathrm{mIm})_{2}\right)$ generate active $\mathrm{CoN}_{\mathrm{x}}$ active sites. Thus, this strategy

combines the advantages from both MOF precursors. The bimetallic MOF strategy was first 
reported in 2015 via using a $\mathrm{Zn} / \mathrm{Co} \mathrm{MOF}$ precursor subject to a heat treatment at $900{ }^{\circ} \mathrm{C}$ followed by an acid-leaching treatment [98]. The resulting Co-N-C catalyst is able to achieve a high surface area with well-dispersed $\mathrm{CoN}_{\mathrm{x}}$ active sites. An increase of $\mathrm{Zn}$ in the MOF crystals resulted in an increased BET surface area from $270 \mathrm{~m}^{2} / \mathrm{g}$ to $2148 \mathrm{~m}^{2} / \mathrm{g}$, but decreased degree of graphitization in corresponding catalysts. Due to a balance between surface areas, nitrogen contents, and highly dispersed $\mathrm{CoN}_{\mathrm{x}}$ active sites, the best ORR activity in $0.1 \mathrm{M} \mathrm{KOH}$ was found in a $20 \mathrm{~mol} \% \mathrm{Zn}^{2+}$ in $\mathrm{ZIF}-67$ catalysts yielding an onset potential of $-0.08 \mathrm{~V}(v s . \mathrm{Ag} / \mathrm{AgCl})$ and a half-wave potential of $-0.15 \mathrm{~V}$ (vs. $\mathrm{Ag} / \mathrm{AgCl})$.

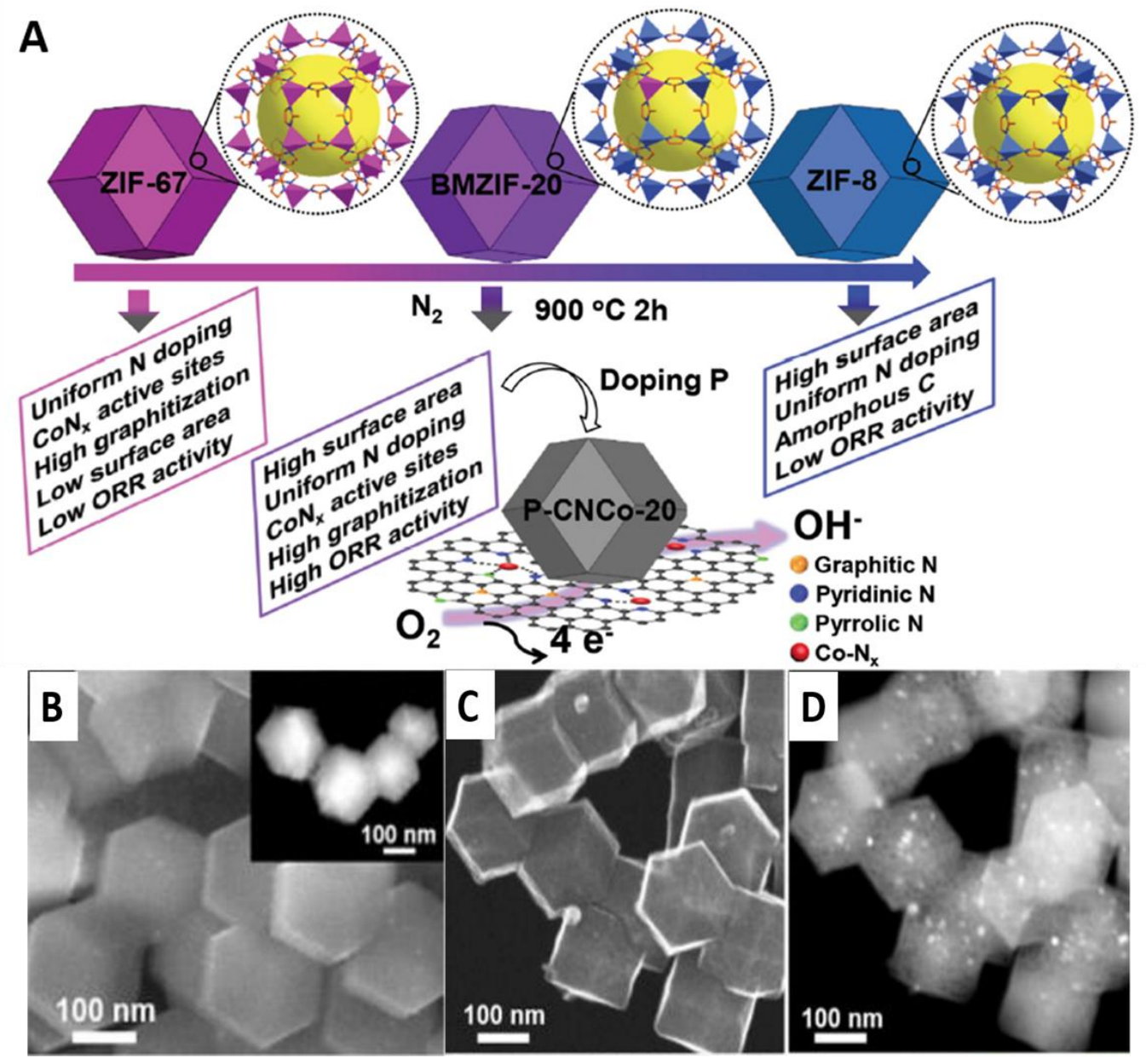


Figure 4. (A) Schematic illustration of Co/ZIF-8-derived ORR catalysts with one step carbonization. Reprinted with permission from Ref. [98]. Copyright 2015, Wiley-VCH. (B) SEM and STEM images of Co/ZIF-8 precursors and (C, D) catalysts. Reprinted with permission from Ref. [99]. Copyright 2015, American Chemical Society.

As for bimetallic MOF crystal-derived catalysts, one of challenge is to avoid the formation of inactive Co aggregates due to their negative effects on ORR activity such as decreased surface areas and increased chance to contaminate membrane and ionomer in fuel cell cathodes. Recently, a new synthetic strategy was developed to control Co doping and realize uniform carbon morphologies without Co agglomeration (Figure 5) [100]. With a less than 5 mol\% ratio of $\mathrm{Co}^{2+}$ doping into ZIF-8, no Co metals were observed in the final catalysts after heating treatment. No any acid-leaching is required, capable of generating a high BET surface area above $1000 \mathrm{~m}^{2} / \mathrm{g}$ along with superior ORR activity (half wave potential: $0.90 \mathrm{~V}$ in $0.1 \mathrm{M} \mathrm{KOH}$ ) [100]. Zn plays an important role in preventing the agglomeration of Co during pyrolysis by spatially separating the Co atoms, and then evaporates out during pyrolysis without introducing new metal phase. However, if a $\mathrm{Co}^{2+}$ content is larger than $10 \mathrm{~mol} \%$, metallic Co nanoparticles appear, which were significantly enwrapped in the carbon structures with reduced BET surface areas. 


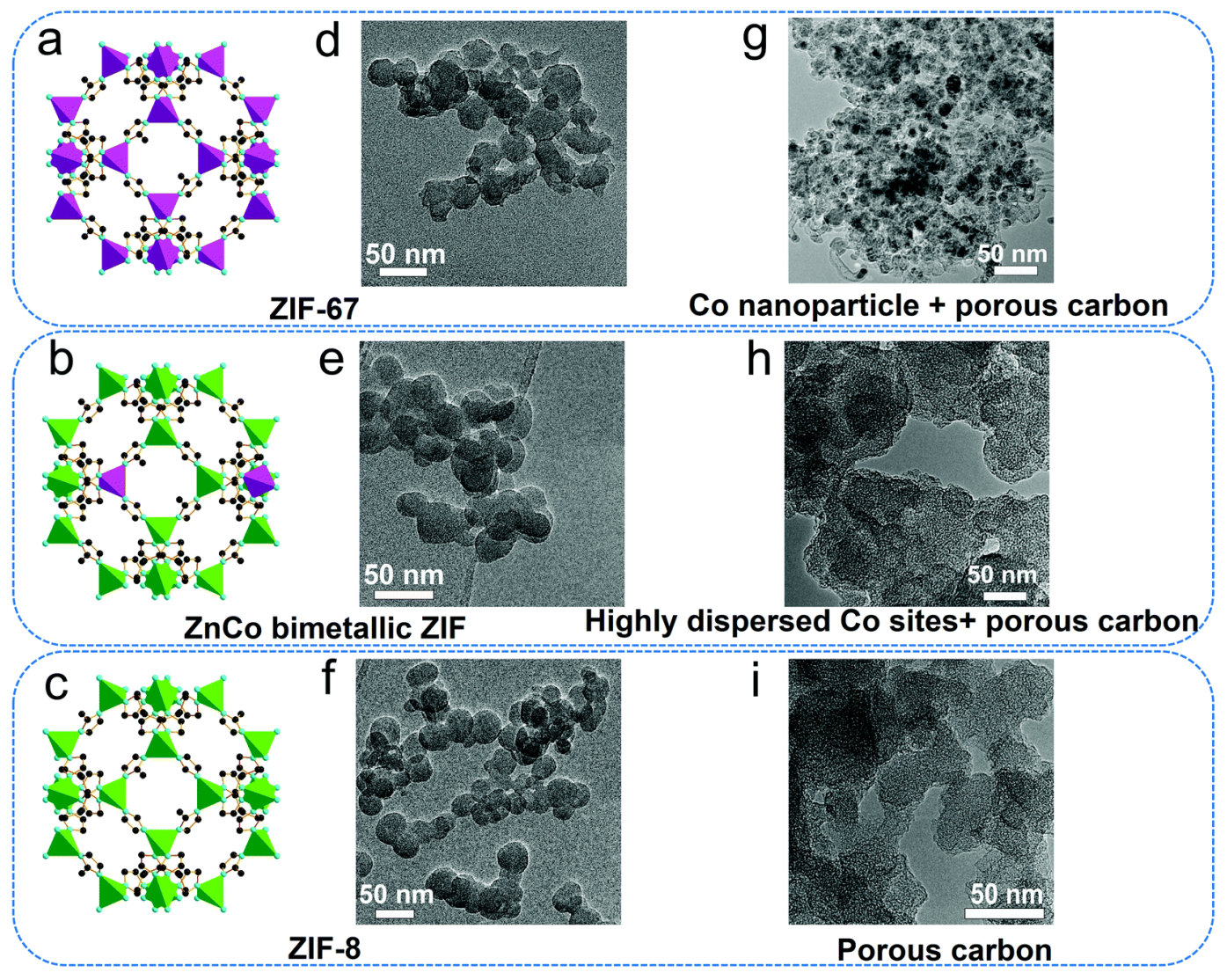

Figure 5. Crystal structures (a-c) and TEM images (d-f) of ZIF-67, ZnCo bimetallic ZIF (ZIF95Zn5Co) and ZIF-8 and TEM images (g-i) of the corresponding catalysts derived by pyrolysis. The green and purple tetrahedrons represent the $\mathrm{ZnN}_{4}$ and $\mathrm{CoN}_{4}$ structures, respectively. Reprinted with permission from Ref. [100]. Copyright 2016, Royal Society of Chemistry.

In terms of durability, however, cathodes using $\mathrm{Co} / \mathrm{Zn}$ MOF-derived catalysts were suffering poor stability during long-term fuel cell tests with a $45 \%$ loss of current density at a constant 0.5 V for 100 hour. It should be noted that the Co-N-C catalyst directly derived from only Co containing ZIF-67 exhibited improved durability under identical testing conditions. This is likely due to the contribution of highly graphitized carbon structures, which have enhanced corrosion resistance relative to amorphous carbon generated from $\mathrm{Co} / \mathrm{Zn}$ MOF precursors [112]. Generally, 
the highly graphitized carbon is beneficial for stability enhancement, but suffers from low activity due to insufficient surface areas and defects for $\mathrm{O}_{2}$ adsorption. Thus, there is a trade-off existing between ORR activity and durability by determine the optimal Co content in the catalysts. However, in the more serious voltage cycling tests in fuel cells, $60 \%$ performance loss of the same ZIF-67 precursor-derived catalysts was still clearly observed within first $50 \mathrm{~h}$, indicating only using highly graphitized carbon still cannot address the overall durability issue of PGM-free cathode in fuel cells [3].

\subsubsection{Fe/Zn containing MOF crystals-derived catalysts}

The strategy of using bimetallic MOF has also been employed to synthesize the more active FeN-C catalysts [106, 113]. Bimetallic Fe-doped ZIF-7 that possesses an open-framework structure with sodalite topology in hexagonal symmetry, formed by bridging benzimidazolate (bim) anions and zinc cations, has been reportedly used to prepare ORR catalysts [106]. By optimizing the temperature and $\mathrm{Zn} / \mathrm{Fe}$ ratio $(x)$ within $\mathrm{Fe}-\mathrm{ZIF}-7$ precursors, the best ORR catalyst containing amorphous carbon interconnected with $\mathrm{N}$-doped carbon nanotubes was obtained by annealing Fe-ZIF-7 precursors $(x=20)$ at $1000{ }^{\circ} \mathrm{C}$ under $\mathrm{N}_{2}$ followed by an acid-leaching treatment. The catalyst showed decent ORR activity, with the half-wave potentials of $0.77 \mathrm{~V}$ in $0.1 \mathrm{M} \mathrm{HClO}_{4}$ and $0.88 \mathrm{~V}$ in $0.1 \mathrm{M} \mathrm{KOH}$. Its activity can be explained by a unique carbon hybrid structure exposing more active sites in amorphous carbon. Compared to catalysts dominated by N-doped carbon nanotubes [109], these amorphous carbon-based catalysts showed higher ORR activity, possibly because the MOF-derived amorphous nanocarbons possess higher active site numbers than those of $\mathrm{N}$-doped carbon nanotubes. This assumption is further supported by recent work in Li's group at Peking University, which demonstrated superior ORR activity in acid for the Fedoped ZIF-8 bimetallic MOF-derived catalysts (Figure 6) [113]. The Fe ${ }^{2+}$ was doped into ZIF-8 
simultaneously during its synthesis by surfactant assisted aqueous solution techniques under $\mathrm{O}_{2-}$ free argon atmosphere. The resulting crystals were carbonized at $1000{ }^{\circ} \mathrm{C}$ to obtain the catalysts without any other tedious post-treatments such as acid-leaching or second heat treatments. After carbonization, the Fe-N-C (Fe-ZIF-8-Ar) catalysts only possessed amorphous carbon structures and a high BET surface area $\left(969 \mathrm{~m}^{2} / \mathrm{g}\right)$ without observing any $\mathrm{Fe}$ aggregate phase or agglomeration from XRD and TEM. On the other hand, a Fe-doped ZIF crystal directly synthesized from the identical solution reaction but exposing to air without protection of Ar. The corresponding Fe-N-C catalyst (Fe-ZIF-8-Ar) had a relatively low BET surface area of $610 \mathrm{~m}^{2} / \mathrm{g}$, containing significant $\mathrm{Fe} / \mathrm{Fe}_{3} \mathrm{C}$ agglomeration along with highly graphitized carbon nanotubes. In addition, a significant difference was found in solution synthesis between Fe-ZIF-8 precursors synthesized with Ar (Fe-ZIF-8-Ar) or without Ar protection (Fe-ZIF-8-air). The Fe-ZIF-8-Ar crystals were homogenously synthesized about $40 \mathrm{~nm}$, while inhomogeneous features of Fe-ZIF8-air nanoparticles were observed with a wide size distribution indicating the poor crystal quality. The XPS results indicate that $\mathrm{Fe}^{2+}$ was oxidized to $\mathrm{Fe}^{3+}$ under air during the solution synthesis. It was concluded that an $\mathrm{O}_{2}$-free environment during the solution synthesis of Fe-ZIF-8 crystals plays a critical role in keeping $\mathrm{Fe}^{2+}$ from oxidizing to $\mathrm{Fe}^{3+}$ and in achieving uniformly dispersed $\mathrm{Fe}$ in the final carbon catalysts. In $0.5 \mathrm{M} \mathrm{H}_{2} \mathrm{SO}_{4}$, the Fe-ZIF-8-Ar catalyst showed much higher ORR activity with an onset potential of $0.95 \mathrm{~V}$ and a half wave potential of $0.82 \mathrm{~V}$ compared to the Fe-ZIF-8-air catalyst. This finding indicates that amorphous carbon with less degree of graphitization can provide a very high ORR activity, while catalysts dominated by graphitized carbon nanotube morphology in the presence of $\mathrm{Fe} / \mathrm{Fe}_{3} \mathrm{C}$ particles was not favorable for high ORR activity. The observation supports the hypothesis that ideal Fe-N-C catalysts should present uniformly distributed atomic iron associated active sites such as $\mathrm{FeN}_{4}$ moieties embedded into 
carbon planes [53]. Metallic iron and iron carbides are not necessary for the ORR and commonly yield negative effects. They are generated as by-products due to the agglomeration of iron during carbonization. Thus, minimizing the production of such inactive iron aggregates is proposed to improve the ORR activity and stability. This is also in agreement with a recent work, which removing metallic iron particles from Fe-N-C catalysts is able to significantly to improve ORR activity [128]. However, these results are opposite to the previous observation that high ORR activity resulted from highly graphitized carbon structures catalyzed by $\mathrm{Fe} / \mathrm{Fe}_{3} \mathrm{C}$ during high temperature treatment $[108,116,129-131]$, where $\mathrm{Fe} / \mathrm{Fe}_{3} \mathrm{C}$ particles embedded within highly graphitized carbon shells $[108,132]$. Thus, further elucidating the correlation between carbon structures and their ORR activity is still required to conclude whether $\mathrm{Fe} / \mathrm{Fe}_{3} \mathrm{C}$ and its generated highly graphitized carbon structures are beneficial to ORR activity or not. 

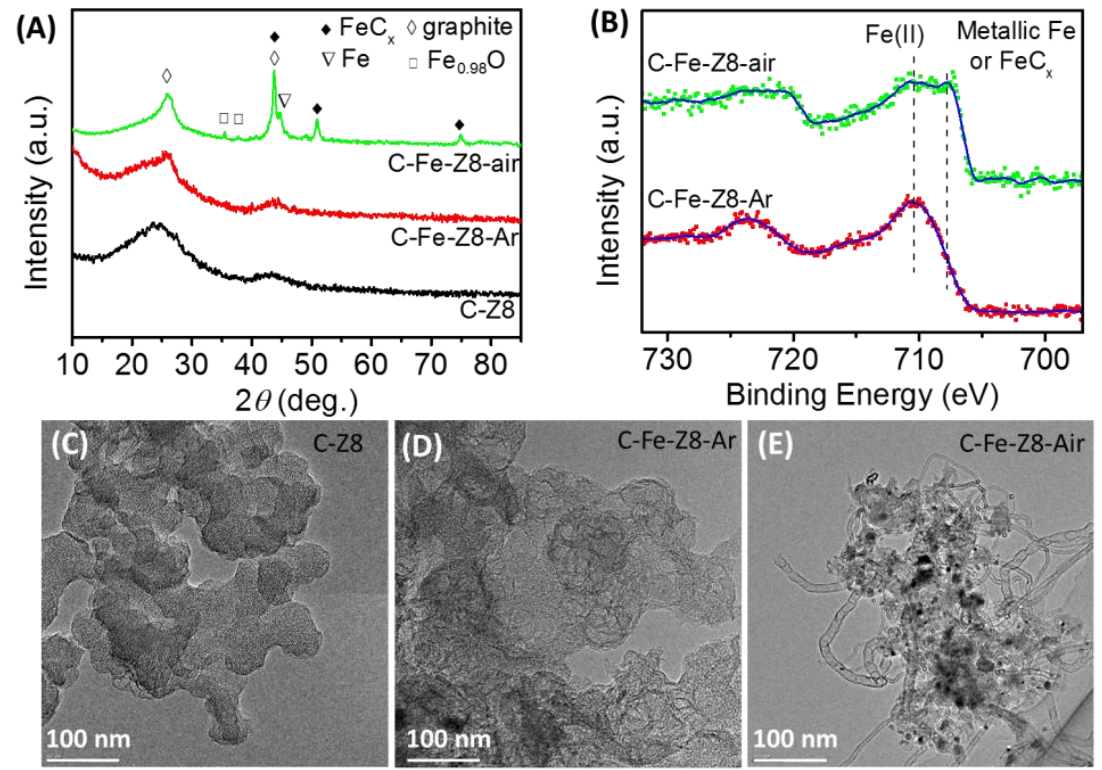

(F)

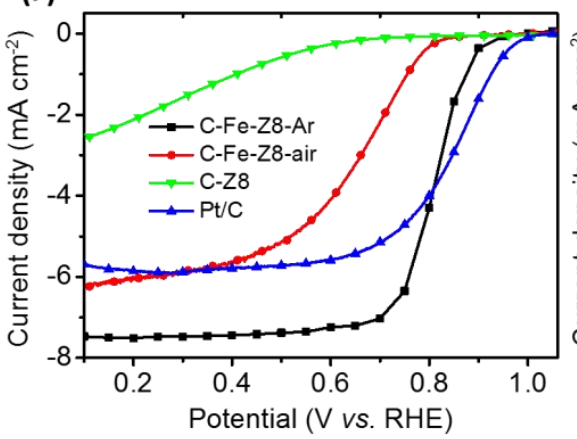

(G)

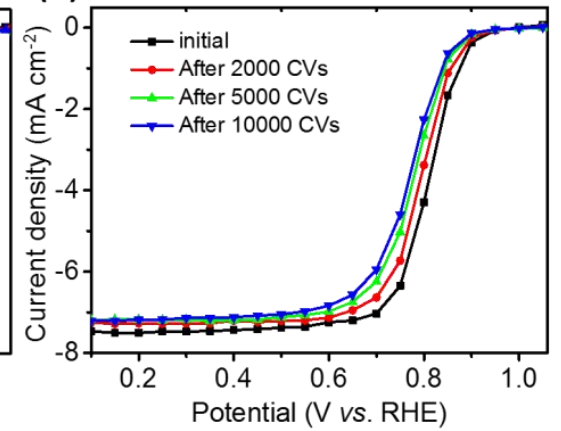

Figure 6. (A) PXRD pattern of the carbonized catalysts derived from ZIF-8 (C-Z8), Fe-ZIF-8-Ar (C-Fe-Z8-Ar), and Fe-ZIF-8 (C-Fe-Z8-air). (B) Fe 2s XPS of carbonized Fe-ZIF-8-Ar and FeZIF-8-air catalysts. TEM images of catalysts pyrolyzed from (C) ZIF-8, (D) Fe-ZIF-8-Ar, (E) Fe-ZIF-8-air. F) ORR Polarization curves of ZIF-8 derived catalysts and Pt/C. (G) ORR activity of Fe-ZIF-8-Ar derived catalysts after conducting cyclic voltammetry at 2000, 5000 and 10000 cycles for stability evaluation. All RRDE results were measured in $\mathrm{O}_{2}$-saturated $0.1 \mathrm{M} \mathrm{HClO}_{4}$ at $1600 \mathrm{rpm}$. Reprinted with permission from Ref. [113]. Copyright 2016, Elsevier Ltd. 


\section{Catalysts derived from MOF hybrid precursors}

MOFs are known for their microporous structure similar to other porous carbon supports like zeolites and carbon blacks. Such micropores can be used to absorb guest molecules for applications such as storage and catalysis. Unlike traditional carbon supports such as Black Pearl and Kejten Black that are mostly inert and inactive for the ORR, MOFs, however, can be directly converted into active carbon catalysts as discussed above. Aiming to further improve the ORR activity of MOF-derived carbon catalysts, MOF hybrid composite precursors have been explored by integrating MOF crystals with additional nitrogen and metal precursors. Therefore, use of MOFs as a support to replace traditional carbon blacks during the synthesis of N-C or M-N-C catalysts may provide significant benefits to generate innovative nanostructures and morphologies.

\subsection{N-C catalysts derived from MOF hybrid precursors}

Nitrogen-doped carbon made using MOF-5 have been studied as active ORR catalysts [84, 95, 96]. Since MOF-5 is synthesized by linking $\mathrm{Zn}^{2+}$ and terephthalic acid, which does not contain any nitrogen atoms, additional nitrogen precursors are required during the synthesis. For example, MOF-5/g- ${ }_{3} \mathrm{~N}_{4}$ was used to create nitrogen-doped carbon catalysts via an in situ growth strategy, in which melamine was introduced into porous MOF-5 derived carbon and then polymerized to $\mathrm{g}-\mathrm{C}_{3} \mathrm{~N}_{4}$ at $550{ }^{\circ} \mathrm{C}$ embedded into the porous carbon matrix [133]. The subsequent high temperature treatment at $900{ }^{\circ} \mathrm{C}$ under $\mathrm{Ar}$ facilitated nitrogen doping into carbon lattices to generate active $\mathrm{N}-\mathrm{C}$ catalysts. This catalyst contains 7 at $\% \mathrm{~N}$ with improved ORR activity in 0.1 $\mathrm{M} \mathrm{KOH}$ compared to the catalyst from directly pyrolyzed melamine and MOF-5 with low nitrogen contents. Sulfur and nitrogen co-doped porous carbons from MOF-5 composites have also been reported [84]. The MOF-5 was impregnated with urea and dimethyl sulfoxide, then 
pyrolyzed at $900{ }^{\circ} \mathrm{C}$ under $\mathrm{N}_{2}$, yielding sulfur and nitrogen co-doped porous carbon with enhanced activity relative to solely nitrogen-doped one.

MOF hybrid composite precursors can also be achieved by surface coating [91, 102]. An alveoli-like nanocarbons were obtained by pyrolysis of dopamine-coated ZIF- 8 at $800^{\circ} \mathrm{C}$ under argon (Figure 7) [91]. Instead of the often observed shrunken rhombic dodecahydron morphology, the dopamine-coated ZIF-8 derived nanocarbons showed aggregates of small balloon-like particles similar to the structure of alveoli, and the carbon-shells of the particles derived from dopamine were clearly observed by TEM. The thickness of the dopamine-coated shells can be adjusted by controlling the coating time. Although the BET surface area of alveolilike carbons is reduced to $512 \mathrm{~m}^{2} / \mathrm{g}$ compared to ZIF-8 derived carbon $\left(881 \mathrm{~m}^{2} / \mathrm{g}\right)$, the average pore diameters increased from $1.78 \mathrm{~nm}$ to $3.92 \mathrm{~nm}$. The more positive half-wave potential $(0.81$ V) of these alveoli-like nanocarbons for the ORR in alkaline environments is measured compared to individual ZIF-8 precursor-derived carbon, which was related to the increase of graphitic- $\mathrm{N}$ from dopamine and the unique pores for improved mass transfer. 


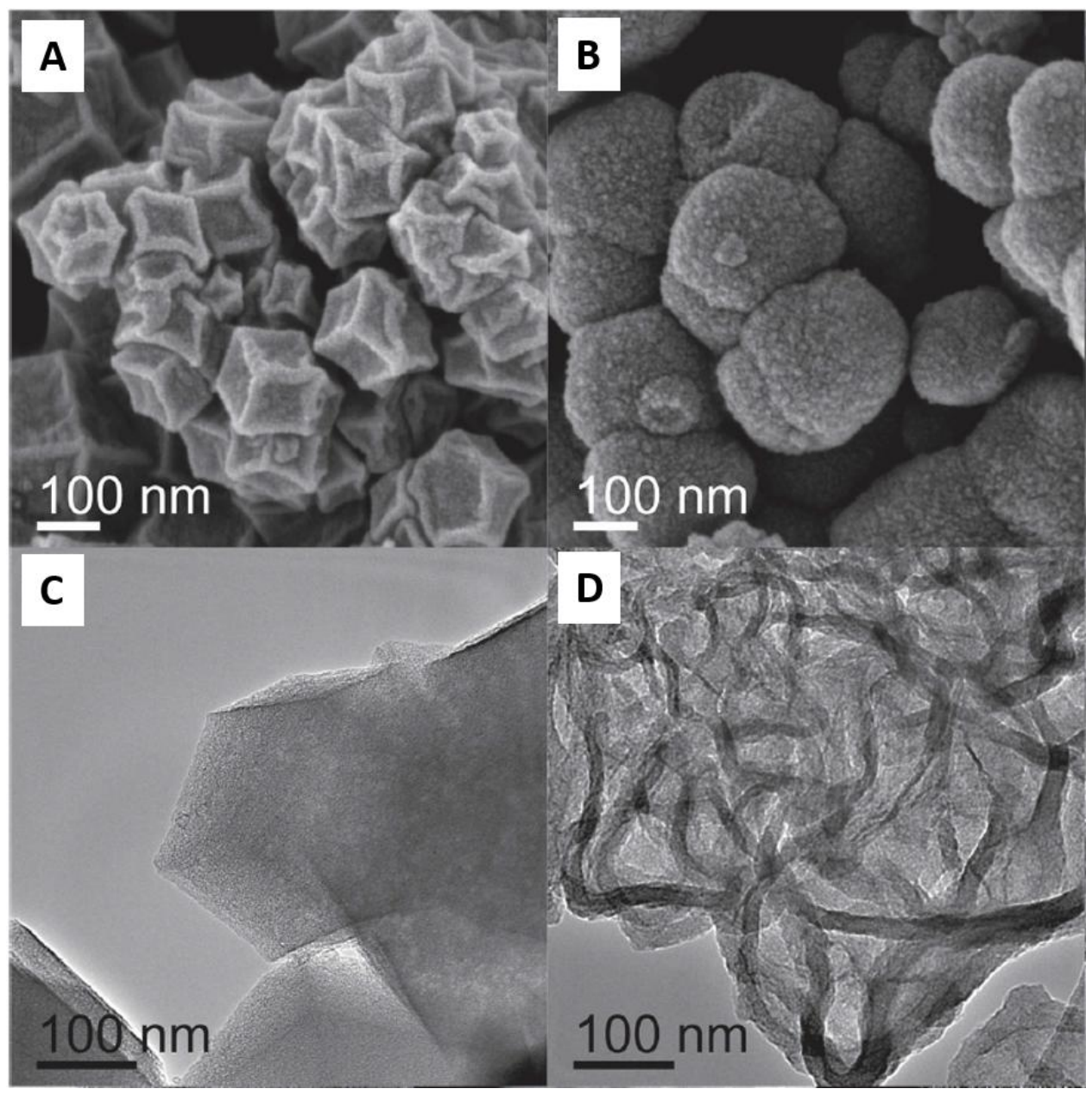

Figure 7. HR-SEM and HR-TEM images of (A, C) ZIF-8 derived carbon and (B,D) dopaminecoated ZIF-8. Reprinted with permission from Ref. [91]. Copyright 2015, Wiley-VCH.

\subsection{M-N-C catalysts derived from MOF hybrid precursors}

The catalytic effects of transition-metals on graphitization of hydrocarbon compounds at high temperatures are useful for preparing novel carbon materials with unique porous structure. Honeycomb-like open porous nanocarbons have been prepared by heating a MOF hybrid precursor consisting of MIL-101- $\mathrm{NH}_{2}$ with Co coordinating compounds encapsulated in the pores. The guest molecules, thiourea $(\mathrm{Tu})$ and $\mathrm{CoCl}_{2}$ were introduced into the pores of MIL-101- 
$\mathrm{NH}_{2}$ via a double phase encapsulation approach (DPEA), in which the hydrophobic phase forces hydrophilic disperse phases containing guest molecules into the pores of hydrophilic MIL-101$\mathrm{NH}_{2}$ to avoid surface absorption (Figure 8). The thiourea and $\mathrm{CoCl}_{2}$ form the $\mathrm{Co}(\mathrm{Tu})_{4} \mathrm{Cl}_{2}$ coordinating compound within the pores of MIL-101- $\mathrm{NH}_{2}$, which is converted into $\mathrm{Cog}_{9} \mathrm{~S}_{8}$ embedded in the graphitic carbon through a high temperature treatment. The formation of honeycomb-like pores was explained by the generation of large amounts of $\mathrm{N}$ - and $\mathrm{S}$ - containing gas, expanding the original pores of the MOF as well as doping into carbon lattices. Although $\mathrm{Co}_{9} \mathrm{~S}_{8}$ nanoparticles dominated in the carbon catalysts exhibited poor activity for the ORR in 0.1 M KOH [134], the honeycomb-like nanocarbon catalysts generated improved activity with an onset potential of $-0.05 \mathrm{~V}(v s . \mathrm{Ag} / \mathrm{AgCl})$ and a half-wave potential of $-0.17 \mathrm{~V}(v s . \mathrm{Ag} / \mathrm{AgCl})$ relative to Co-free $\mathrm{N}-\mathrm{C}$ catalysts. This is due to a synergetic effect from $\mathrm{N}$ - and S-doping, high graphitization and large surface area $\left(1791 \mathrm{~m}^{2} / \mathrm{g}\right)$ carbon with increased active sites and favorable mass diffusion. 

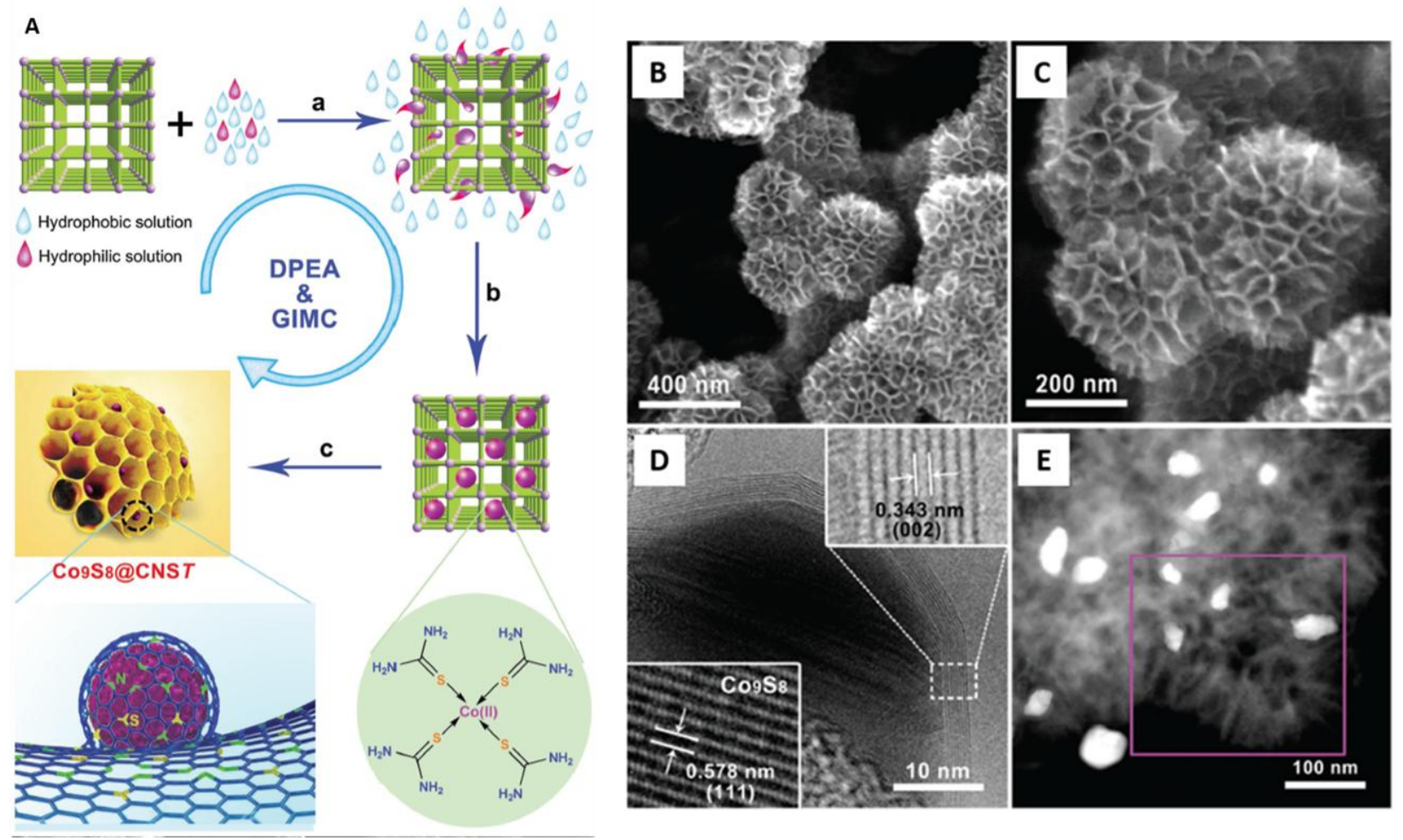

Figure 8. (A) Schematic illustration of the double phase encapsulation approach (DPEA) and guest-induced morphology control (GIMC) by introducing guest molecules into MOFs (a), coordination of thiourea with cobalt chloride in the pores of MIL-101- $\mathrm{NH}_{2}$ (b) and high temperature conversion of guest-MOF hybrid precursors into honeycomb-like porous carbon with encapsulated $\mathrm{Co}_{9} \mathrm{~S}_{8}(\mathrm{c})$. (B, C) SEM images of honeycomb-like nanocarbon catalysts. (D) TEM image of $\mathrm{Co}_{9} \mathrm{~S}_{8}$ nanoparticles embedded in the graphitic carbon layers of honeycomb-like nanocarbon catalysts. E) STEM image of honeycomb-like nanocarbon catalysts with obvious $\mathrm{Co}_{9} \mathrm{~S}_{8}$ nanoparticles. Reprinted with permission from Ref. [101]. Copyright 2016, Wiley-VCH.

Compared to other MOF precursors, owing to its high surface area, high nitrogen content, and microporous structure, ZIF-8 has often been studied as a carbon support to replace traditional carbon blacks for the synthesis of Fe-N-C catalysts. Dodelet's group first employed 
ZIF-8 as a microporous support to replace Black Pearl 2000 via ball milling ZIF-8 with iron acetate(II) and 1,10-phenanthroline followed by pyrolysis under $\mathrm{Ar}$ and $\mathrm{NH}_{3}$ heat treatments [73]. When the temperature of the first pyrolysis under $\mathrm{Ar}$ increased from $400{ }^{\circ} \mathrm{C}$ to $700{ }^{\circ} \mathrm{C}$, they found that the BET surface area of catalysts decreased from $1237 \mathrm{~m}^{2} / \mathrm{g}$ to $106 \mathrm{~m}^{2} / \mathrm{g}$. However, at $1050{ }^{\circ} \mathrm{C}$, the surface area of the catalysts started increasing and reached $478 \mathrm{~m}^{2} / \mathrm{g}$. According to the changes of BET surface areas, it is likely that, above $500{ }^{\circ} \mathrm{C}, \mathrm{Zn}(\mathrm{CN})_{2}$ is formed due to the release of $\mathrm{CN}$ fragments from the decomposition of $\mathrm{Zn}$ (II)-imidazolate linkage, which blocks the pores; however, above $800{ }^{\circ} \mathrm{C}, \mathrm{Zn}(\mathrm{CN})_{2}$ would be decomposed to volatile $\mathrm{Zn}$ and $\mathrm{CN}$ fragments, resulting in an increase in the surface area of catalysts. After pyrolysis at $1050{ }^{\circ} \mathrm{C}$ and subsequent $\mathrm{NH}_{3}$ treatment at $950^{\circ} \mathrm{C}$, the best catalyst possessed a BET surface area of $964 \mathrm{~m}^{2} / \mathrm{g}$ containing high micropore surface area of $814 \mathrm{~m}^{2} / \mathrm{g}$. This ZIF- 8 composite precursor-derived Fe$\mathrm{N}-\mathrm{C}$ catalyst, for the first time, achieve the highest volumetric activity of $230 \mathrm{~A} / \mathrm{cm}^{3}$ and a peak power density of $0.91 \mathrm{~W} / \mathrm{cm}^{2}$ in the cathode of a $\mathrm{H}_{2}-\mathrm{O}_{2}$ fuel cell (Figure 9). Notable, the powder density generated at $0.6 \mathrm{~V}$ is $0.75 \mathrm{~W} / \mathrm{cm}^{2}$, comparable to that from a Pt cathode with a loading of $0.3 \mathrm{mg}_{\mathrm{pt}} / \mathrm{cm}^{2}$ [73]. The high power is likely due to the use of ZIF-8 as a support in the catalyst facilitating diffusion of ORR-related species within interconnected micropores in comparison to densely agglomerated BP supported catalysts. In addition, the high activity measured with the novel $\mathrm{Fe}-\mathrm{N}-\mathrm{C}$ catalyst is mainly attributed to the increased density of $\mathrm{FeN}_{\mathrm{x}}$ catalytic sites in the highly porous catalyst layers with optimal interfaces with ionomers [135]. It should be noted the iron aggregates clearly observed in Figure $9 \mathrm{~b}$ have been proven inactive for the ORR [113]. They are a by-product of catalyst synthesis during the high temperature treatment. One of current challenge to develop highly active Fe-N-C catalyst is to minimize the generation of such inactive 
iron phases that would cause potential stability issues in fuel cell cathode due to their very likely dissolution.
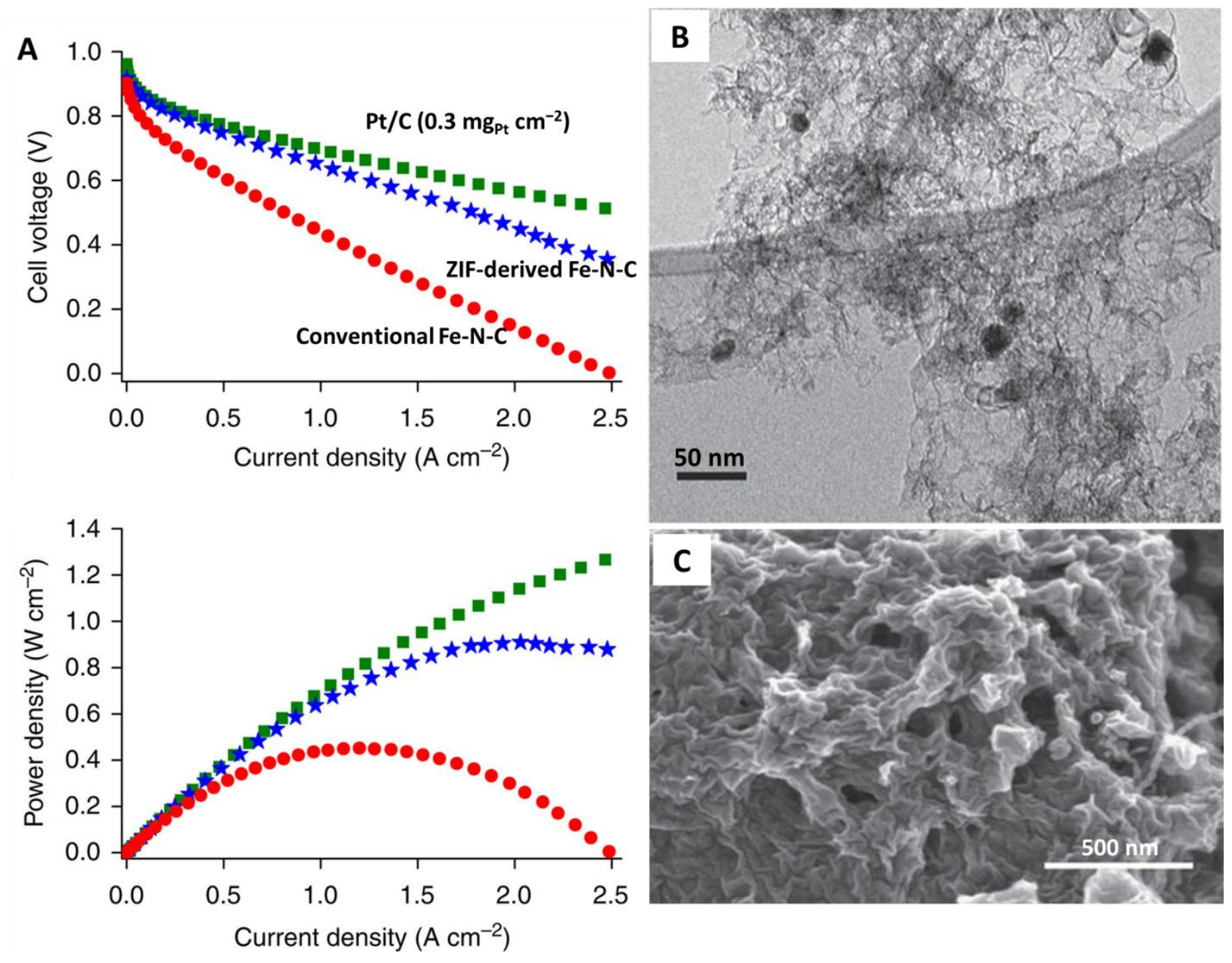

Figure 9. $\mathrm{H}_{2}-\mathrm{O}_{2}$ PEM fuel cell (A) polarization curves and power density curves of Pt (green square) with a loading of $0.3 \mathrm{mg} \mathrm{p}_{\mathrm{p}} / \mathrm{cm}^{2}, \mathrm{ZIF}-8$ supported catalysts (blue star) and BP supported catalysts (red circles) with both $3.9 \mathrm{mg} / \mathrm{cm}^{2}$ loadings at the cathode. (B) TEM and (C) SEM images for the high-performance ZIF-8 derived catalysts. Reprinted with permission from Macmillan Publishers Ltd [Nature Communications] from Ref. [73]. Copyright 2011. 
After successfully demonstrating the feasibility to use a MOF precursor (i.e., cobalt imidazolate) to prepare a high-performance Co-N-C catalyst, Liu et al., further explored Fe-N-C catalysts by using an iron imidazolate (FeIM) framework [115]. The iron imidazolate framework was obtained by heating a ferrocene and imidazole mixture at $150{ }^{\circ} \mathrm{C}$ in an autoclave for four days. Considering the effect of pyrolysis temperature ranging from 700 to $900{ }^{\circ} \mathrm{C}$, it was found that FeIM pyrolyzed at $700{ }^{\circ} \mathrm{C}$ after acid-leaching and $\mathrm{NH}_{3}$ heat treatment exhibited the highest ORR activity. Further employment of ZIF-8 as a host with FeIM (FeIM/ZIF-8) was carried out by ball milling ZIF-8 with FeIM followed by heat treatments at $1050{ }^{\circ} \mathrm{C}$ under $\mathrm{Ar}$ and $950{ }^{\circ} \mathrm{C}$ under $\mathrm{NH}_{3}$ [115]. The MOF composites precursors yielded a highly active Fe-N-C catalysts in acidic electrolyte with enhanced activity $\left(E_{0}\right.$ at $915 \mathrm{~V}$ and $E_{1 / 2}$ at $0.755 \mathrm{~V}$ in $0.1 \mathrm{M} \mathrm{HClO}_{4}$ ) relative to individual FeIM framework derived one. XRD and TEM analysis further indicated that FeIM/ZIF-8 precursors resulted in a lower degree of graphitization and fewer $\mathrm{Fe} / \mathrm{Fe}_{3} \mathrm{C}$ nanoparticles, but higher surface area accessible to active sites. Therefore, the activity improvement is attributed to the combination of higher surface area dominated by micropores, higher pyridinic nitrogen content, and good conductivity derived from FeIM/ZIF-8 composite precursors. Furthermore, a series of Fe-N-C catalsyts were preapared by using various $\mathrm{Zn}$-based zeolitic imidazolate frameworks by choosing four different ligands including ZIFs, $\mathrm{Zn}(\operatorname{Im})_{2}$, $\mathrm{Zn}(\mathrm{mIm})_{2}, \mathrm{Zn}(\mathrm{eIm})_{2}$ and $\mathrm{Zn}(4 \mathrm{abIm})_{2}$ with $\mathrm{ZnO}$ by on-step solid state synthesis at $180{ }^{\circ} \mathrm{C}$ for 18 hours [97]. Then these ZIFs were ball-milled with $5 \mathrm{wt} \%$ tris-1,10-phenanthroline iron(II) perchlorate (TPI) followed by multiple treatments including a heat treatment at $1050{ }^{\circ} \mathrm{C}$ under $\mathrm{Ar}$, an acid-leached treatment, and a final heating treatment with $\mathrm{NH}_{3}$ at $950{ }^{\circ} \mathrm{C}$. Among studied $\mathrm{ZIF}$ precursors, only $\mathrm{Zn}(\operatorname{Im})_{2}$ showed a porous structure. However, all of final catalysts became 
porous and had amorphous carbon structures after high temperature treatment. In particular, $\mathrm{Zn}(\operatorname{Im})_{2}$ TPI-derived catalysts showed the lowest nitrogen content, the highest degree of graphitization, and the most dominant $\mathrm{Fe}_{3} \mathrm{C}$ phases, thus yielding the lowest activity among the four catalysts. Although it is reported that the core-shell $\mathrm{Fe}_{3} \mathrm{C} /$ carbon layers structure could improve the stability of the ORR catalysts, it is still not clear yet. Interestingly, the $\mathrm{Zn}(\mathrm{mIm})_{2}$ TPI-derived catalysts with the largest BET surface area $\left(1277 \mathrm{~m}^{2} / \mathrm{g}\right)$ did not show the best activity. The $\mathrm{Zn}(\mathrm{eIm})_{2} \mathrm{TPI}$-derived catalyst with a relatively lower BET surface area of 920 $\mathrm{m}^{2} / \mathrm{g}$ had the best activity in RDE tests showing an onset potential of $0.91 \mathrm{~V}$ and half-wave potential of $0.78 \mathrm{~V}$ in the acid electrolyte. It was concluded that porosity in ZIF precursors is not required to obtain a porous catalyst since the evaporation of Zn during carbonization could also generate micropores and mesopores. However, in fuel cell tests, the high-surface-area $\mathrm{Zn}(\mathrm{mIm})_{2}$ TPI-derived catalyst had a higher volumetric current density $\left(51.5 \mathrm{~A} \mathrm{~cm}^{-3}\right.$ normalized with $\mathrm{O}_{2}$ and $\mathrm{H}_{2}$ pressure to 1 bar) than that of $\mathrm{Zn}(\mathrm{eIm})_{2} \mathrm{TPI}$-derived catalysts above $0.75 \mathrm{~V}_{\mathrm{iR} \text {-free, }}$, indicating the important role of high surface area and porosity for high current domain. Further performance optimization of $\mathrm{Zn}(\mathrm{mIm})_{2}$ TPI-derived catalysts in fuel cell tests showed that the addition of Ketjen Black in the cathode could decrease the internal resistance, suggesting the carbon directly derived from ZIF cannot provide sufficient electron conductivity [136]. 


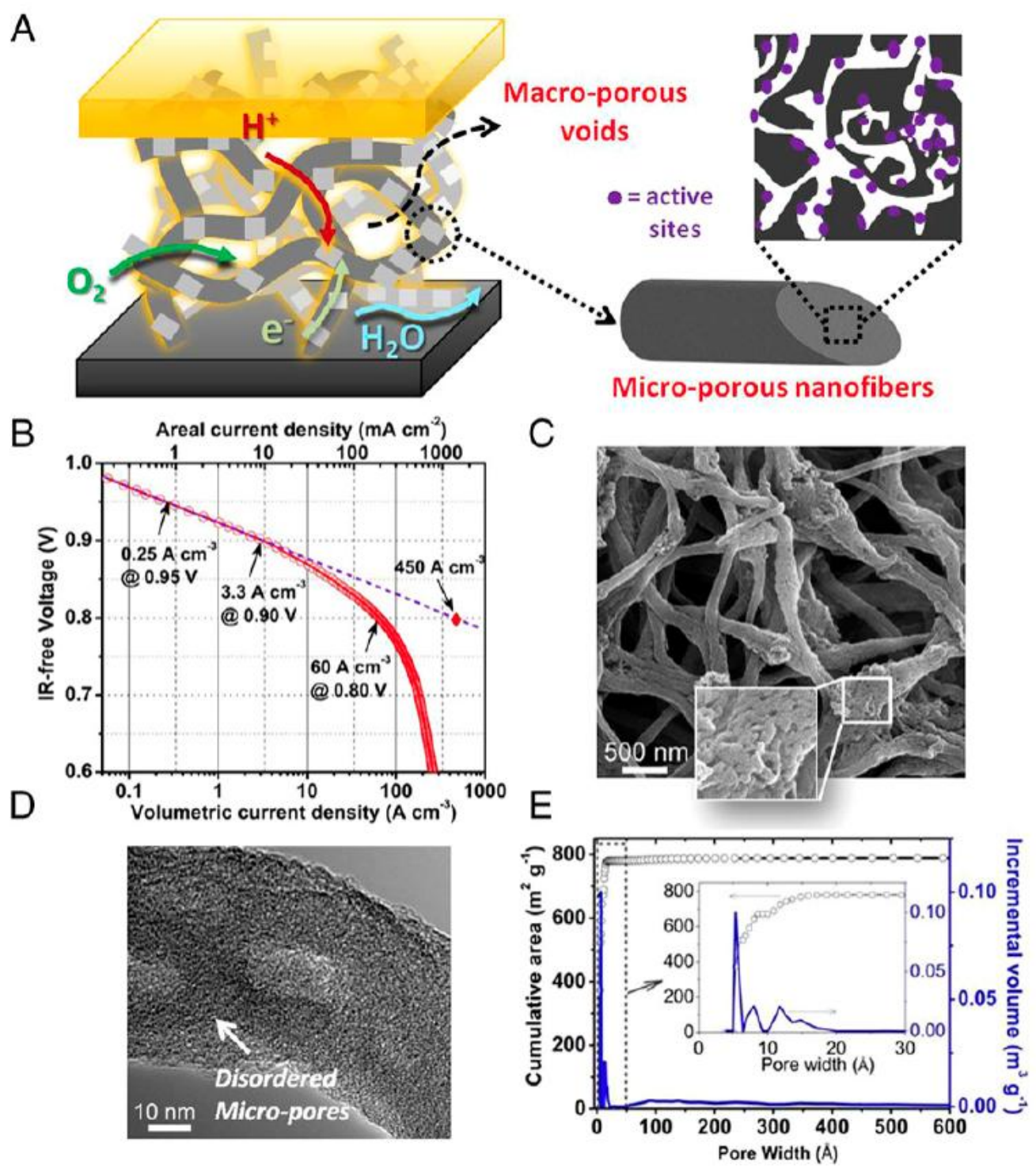

Figure 10. (A) Schematic illustration of the porous structure of carbon nanofiber ORR catalysts with active sites located in the micropores. (B) Volumetric activity with iR-correction of ZIF-8based carbon nanofiber catalysts for ORR in fuel cells at $80{ }^{\circ} \mathrm{C}$ with both 1.5 bar pressure of hydrogen and oxygen, respectively, including 0.5 bar water vapor pressure for both gases. (C) SEM images of the porous morphology of ZIF-8 based carbon nanofiber catalysts. (D) TEM images of the micropores within ZIF-8-based carbon nanofiber catalysts. (E) Pore distribution of 
ZIF-8-based carbon nanofiber catalysts. Reprint with permission from the Ref [72]. Copyright (2015) National Academy of Sciences.

In order to enhance mass/charge transfer properties of MOF-derived catalysts, a ZIF-8 based catalyst with a novel carbon nanofibrous network morphology has been reported for a fuel cell cathode (Figure 10) [72]. The nanofiber structures were fabricated using an electrospining method. A DMF slurry of ZIF-8, TPP, polyacrylonitrile and poly(methyl methacrylate) was used for electrospinning, followed by a pyrolysis with ammonium to produce the carbon nanofiberrich catalysts. The individual carbon nanofibers had diameters around 100-200 nm with the presence of some larger "knots" on the fibers. The best carbon nanofiber catalyst exhibited an onset potential of $0.93 \mathrm{~V}$ and a half wave potential of $0.80 \mathrm{~V}$ in $0.5 \mathrm{M} \mathrm{H}_{2} \mathrm{SO}_{4}$ during RDE tests, which is similar to state of the art PGM-free catalysts. A volumetric activity of $60 \mathrm{~A} \mathrm{~cm}^{-3}$ at 0.8 $\mathrm{V}_{\mathrm{iR}-\text { free }}$ was experimentally determined in fuel cell tests, which is much higher than that of conventional Fe/ZIF-derived ORR catalysts. The high volumetric activity of this catalyst was mainly attributed to its highly porous structure and high level of graphitization of the carbon fibers. The dominating micropores ( $84 \%$ in total pore volume) were made by the carbonization of uniformly dispersed ZIF-8 in the nanofibers. In addition, the highly graphitized nanofibers from polymer precursors improved electron conductivity in the catalysts. Therefore, the combination of dominant micorpores and highly graphitic nanocarbons is able to yield a significantly improved catalytic performance especially in real fuel cell tests involved many factors including catalytic activity, interfaces, and mass/charge transfers.

\section{Catalysts derived from supported MOF crystal composite precursors}


In previous part, MOF crystals were used as an alternative support to prepare $\mathrm{N}-\mathrm{C}$ or $\mathrm{M}-\mathrm{N}-\mathrm{C}$ catalysts. Oppositely, here, we summarize another approach to design MOF composite precursors for catalyst synthesis. Instead of being supports, MOF crystals were supported by directly in-situ growing them onto various substrates or templates. The general motivation is to minimize the possible aggregation of MOF crystals during the thermal carbonization. It has been observed that MOF crystal particles tend to randomly aggregate into large particles during the carbonization; although crystal shape is retained, the effective surface area for the ORR is reduced. Thus, it would be desirable to control the dimensions and assembly of MOF crystal precursors. Recently, a variety of approaches have been developing by employing additional templates or substrates to prepare highly ordered MOF crystal assembly hybrid precursors. ORR activity enhancement of these superstructured MOF hybrid derived-catalysts benefit from the increase in effective surface areas with more exposure of active sites. In addition, the yielded hierarchical pore structure are able to facilitate mass and charge transfers in real fuel cell cathodes.

\subsection{Nanocarbon supported MOF crystals hybrid}

Graphene oxide (GO) has been used to support ZIF-8 crystals, which was explored as a precursor for preparing catalysts [74]. Typically, ZIF-8 crystals were grown on the surface of GO with the assistance of poly(vinyl pyrrolidone) that is able to coordinate $\mathrm{Zn}^{2+}$ and enhance the uniformity of ZIF-8 nucleation. As a result, a sandwich-like ZIF-8/graphene oxide hybrid was fabricated as shown in Figure 11. After pyrolysis at $800{ }^{\circ} \mathrm{C}$ under inert gas and acid-leaching, the resulting nitrogen-doped porous carbon showed sheet-like morphology and improved ORR activity with an onset potential of $-0.02 \mathrm{~V}(v s . \mathrm{Ag} / \mathrm{AgCl})$ and a half-wave potential of $-0.12 \mathrm{~V}(v s . \mathrm{Ag} / \mathrm{AgCl})$ in $0.1 \mathrm{M} \mathrm{KOH}$. When compared to individual ZIF-8-derived catalysts, the activity enhancement 
observed with the ZIF-8/GO is attributed to high electrical conductivity of reduced GO (rGO) [137], increased surface area, and more nitrogen doping. In addition to GO, carbon nanotubes (CNT) were also extensively studied as supports for PGM-free catalysts [36, 138, 139]. Likewise, they were used to support ZIF-8 for catalyst synthesis [75, 90]. Ge et al. developed the ZIF8/CNT precursors via in situ growth of ZIF-8 crystals on carbon nanotubes modified with carboxyl groups [75]. The carbon nanotubes were enveloped by a dense growth of ZIF-8 crystals on their surface, forming a unique "grape-bunch" morphology (Figure 12). After pyrolysis at $1000{ }^{\circ} \mathrm{C}$ under inert gas, amorphous $\mathrm{N}$-doped carbon derived from ZIF-8 covering onto carbon tubes was obtained, resulting in superior activity with an onset potential of $1.03 \mathrm{~V}$ and a half wave potential of $0.89 \mathrm{~V}$ in $0.1 \mathrm{M} \mathrm{KOH}$. This is likely due to synergetic effects between nitrogen-doped carbon amorphous carbon and highly graphitized nanocarbon to improve surface areas, enhance electron conductivity, and corrosion resistance simultaneously. 

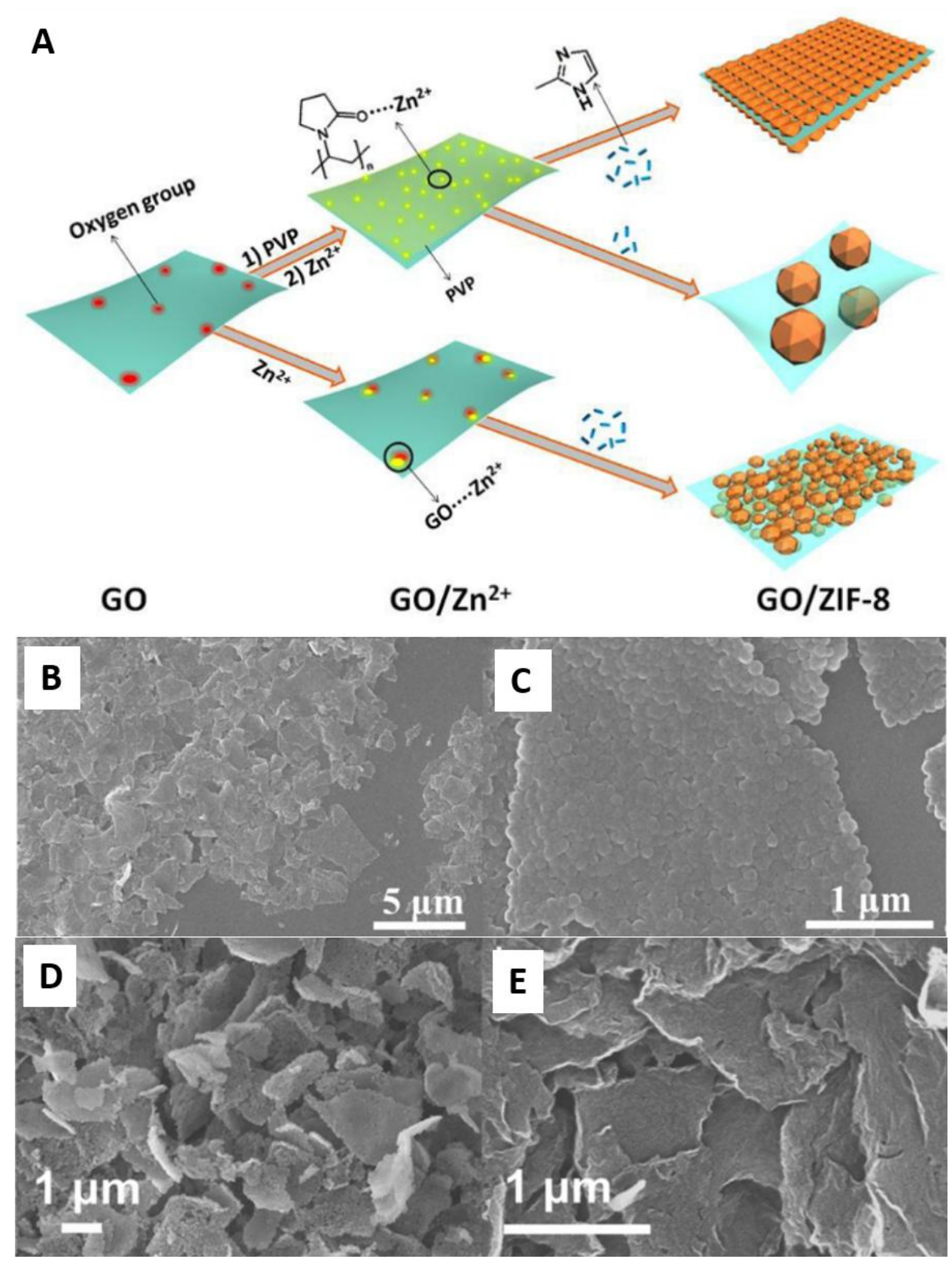

Figure 11. (A) Schematic illustration of a synthetic approach to achieve uniformly coated ZIF-8 crystals a graphene oxide surface with the help of PVP and large excess amounts of 2methylimidazole. SEM images of ZIF-8/graphene oxide (B, C and D) precursors and ZIF8/graphene oxide catalysts (E). Reprinted with permission from Ref. [74]. Copyright 2014, Wiley-VCH. 


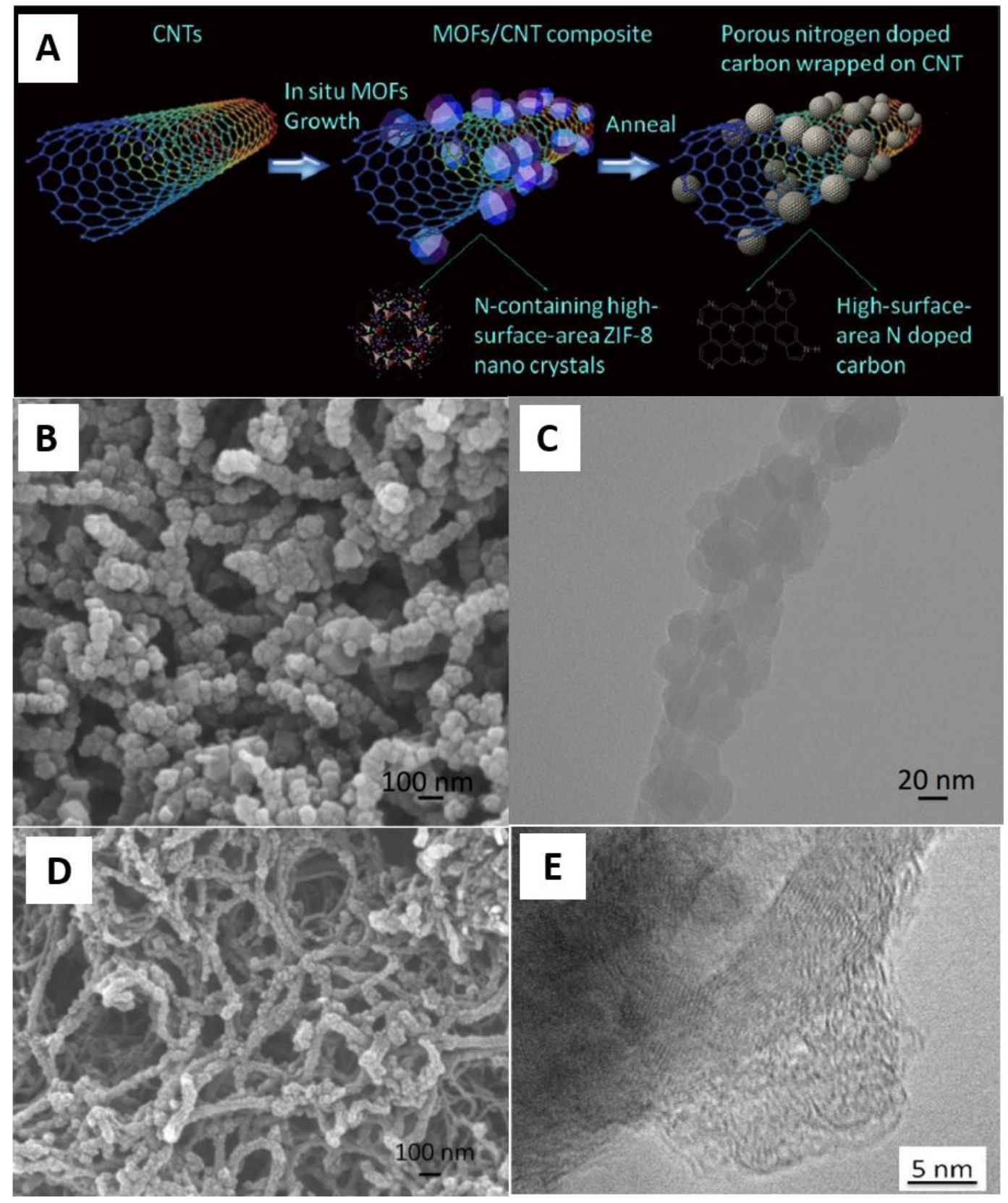

Figure 12. (A) Synthesis process for carbon nanotube/ZIF-8 derived N-doped carbon catalysts for the ORR. SEM and TEM images of ZIF-8 crystal grape-bunch morphology using in situ growth on the carbon nanotubes $(\mathrm{B}, \mathrm{C})$ before carbonization as well as $(\mathrm{D}, \mathrm{E})$ after carbonization. Reprinted with permission from Ref. [75]. Copyright 2015, Elsevier Ltd. 


\subsection{Non-carbon Templates}

Apart from highly electrical conductive nanocarbon supports, non-carbon supports were also studied to template MOF crystals for catalyst preparation. Co/Zn-ZIF crystals are arrayed onto the surface of cobalt aluminum layered double hyroxide (CoAl-LDH) microplates to assemble two dimensional MOF hybrid precursors (Figure 13) [100, 112].
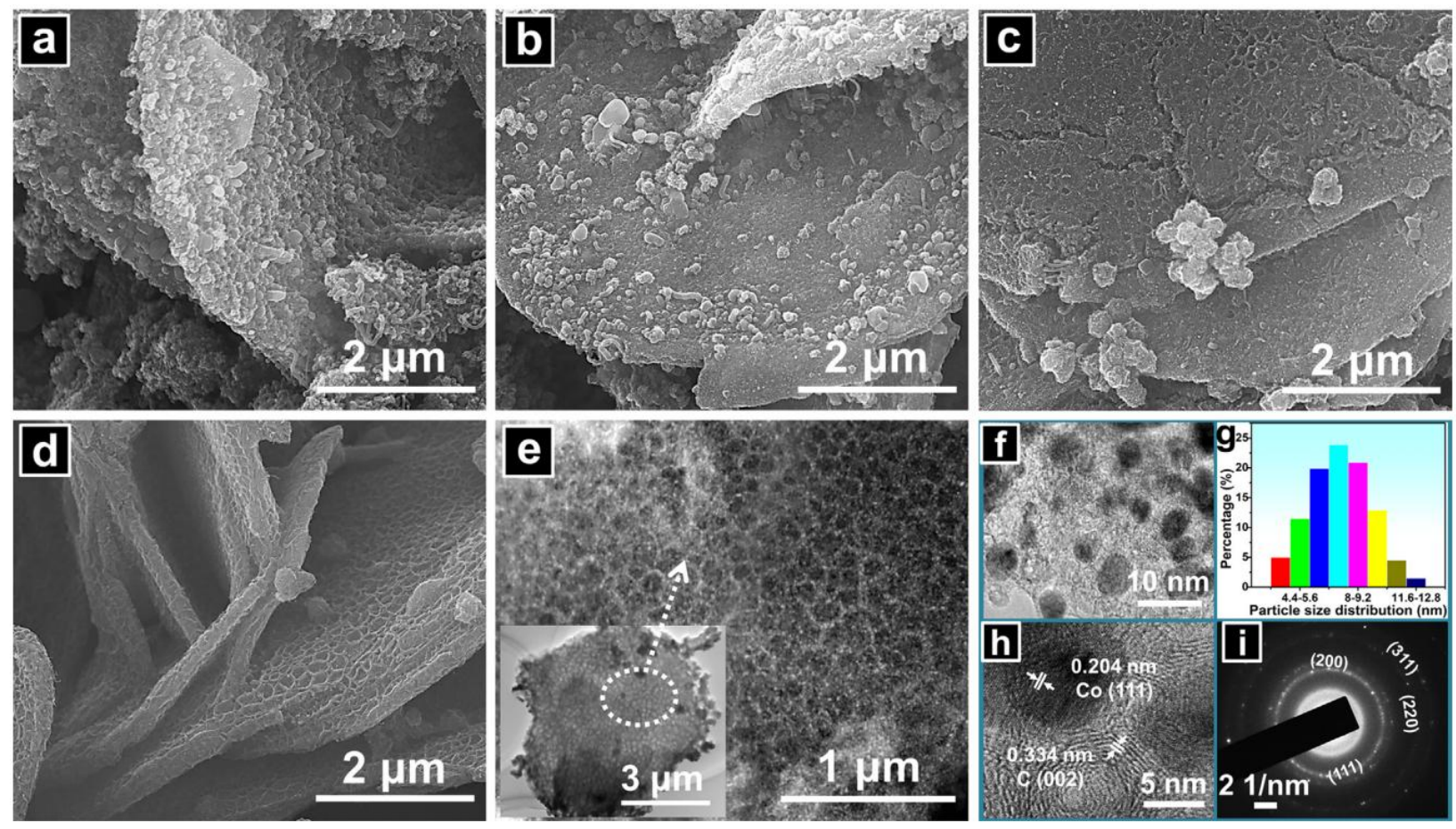

Figure 13. SEM images of (a) CoAl-CoZn-0.25, (b) CoAl-CoZn-0.5, (c) CoAl-CoZn-1, and (d) CoAl-CoZn-2. (e) STEM image of CoAl-CoZn-2. (f, h) HR-TEM images of CoAl-CoZn-2, (g) its corresponding particle size and (i) its corresponding SAED pattern. Reprinted with permission from Ref. [100] Copyright 2016, Elsevier Ltd. 
The morphology of the catalysts can be tuned by the ratio of $\mathrm{Co}^{2+} / \mathrm{Zn}^{2+}(x)$ during precursor synthesis. After pyrolysis, low $x$ values $(<0.5)$ lead to irregular carbon nanoparticles being observed on the surface of CoAl-LDH microplates, while honeycomb-like porous structures appeared on the surface of the microplatete at higher $x$ values. LDH@ZIF-CoZn-2 $(x=2)$ performed the best ORR activity in alkaline electrolyte among all catalysts with various $\mathrm{Co}^{2+} / \mathrm{Zn}^{2+}$ ratios; it also had the highest electron transfer number (3.96) and diffusion-limiting current. The high activity was correlated with unique carbon structures simultaneously containing high graphitization catalyzed by Co and high surface areas due to the evaporation of zinc.

Unique 1D superstructured MOF composite precursors have been prepared by the direct growth of MOFs onto nanowires [93]. It was reported that ZIF-8 directly grew on ultrathin tellurium (Te) nanowires with a controlled thickness, and these hybrid precursors were able to be further converted into porous carbon nanofibers at $1000{ }^{\circ} \mathrm{C}$ under inert gas, which Te was evaporated to form hollow structures due to the relative low boiling point of $987.8^{\circ} \mathrm{C}$ for $\mathrm{Te}$ (Figure 14). The obtained hollow nanocarbon retained the 1D superstructure resulting in a dramatically increased BET surface area of $2270 \mathrm{~m}^{2} / \mathrm{g}$ when compared to $1481 \mathrm{~m}^{2} / \mathrm{g}$ for ZIF-8derived carbon. In comparison to regular ZIF-8 derived porous carbon, this hollow 1D carbon catalyst showed enhanced ORR activity, probably due to the exposure of more active sites and efficient mass transfer. Overall, although templates can increase the electron conductivity and effective surface area of ORR catalysts, like traditional carbon supports, they are barely active for the ORR, reducing the mass activity of the catalysts. Therefore, the amounts of template in the catalysts must be optimized when employed. 


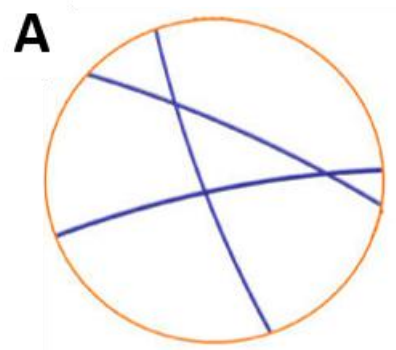

Te Nanowires

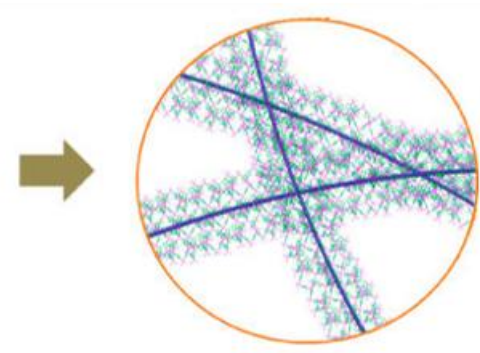

Te@ZIF-8 Nanofibers

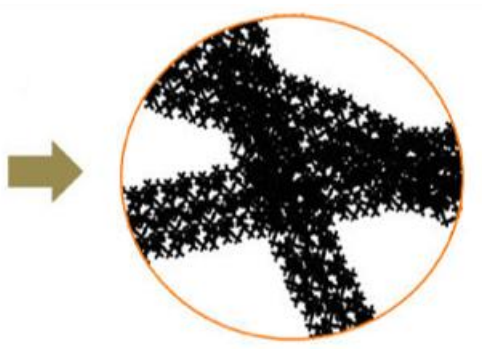

Porous Carbon Nanofibers
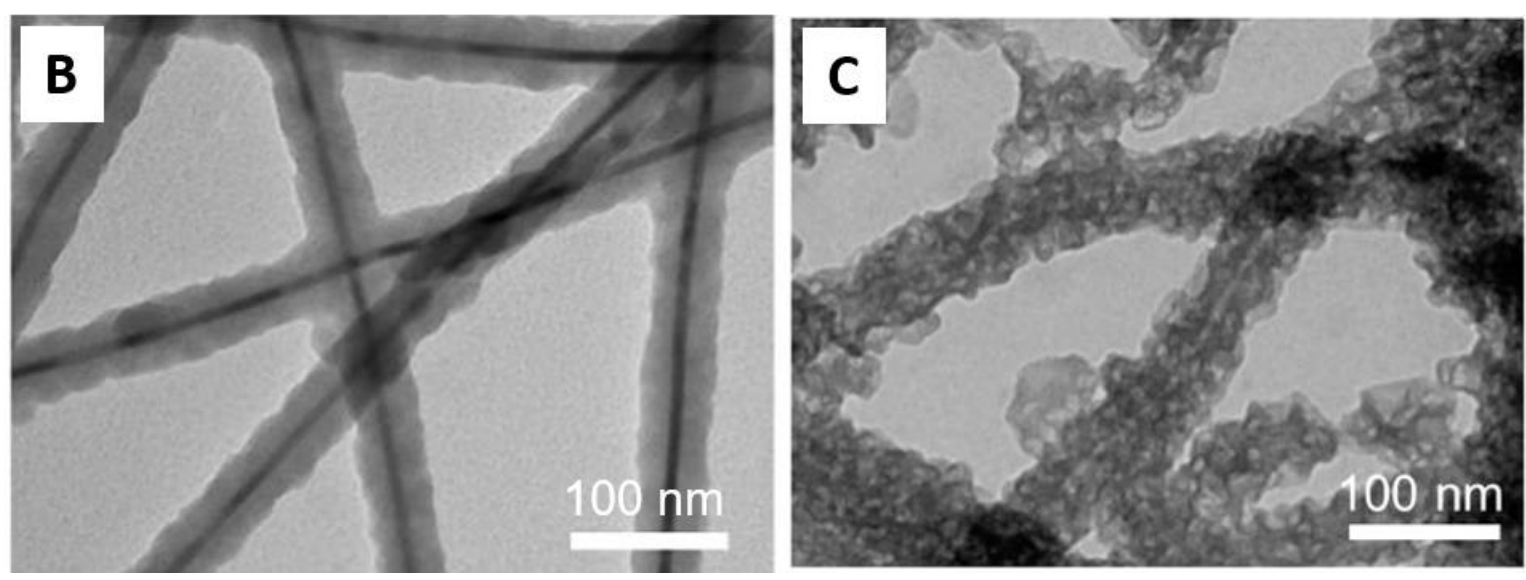

Figure 14. (A) Synthesis of Te nanowire-templated ORR catalysts from ZIF-8. TEM images of (B) Te nanowire/ZIF-8 hybrid precursors with 1D superstructure, and (C) its derived catalysts. Reprinted with permission from Ref. [93]. Copyright 2015, American Chemical Society.

\section{Summary and perspective}

In this account, we provided a comprehensive summary to introducing various approaches that have been developed for designing and synthesizing carbon-based PGM-free oxygen-reduction catalysts by using the unique MOF precursors. It should be noted that most of MOF precursors studied for PGM-free catalysts can be prepared in a low-cost and large-scale manner. MOFs, which simultaneously consist of carbon, nitrogen, and metal sources, are ideal precursors to prepare the most promising carbon-based catalysts for the ORR. The metals used for building 3D 
frameworks can be divided into two types: (i) inactive $\mathrm{Zn}, \mathrm{Al}$, or $\mathrm{Mg}$, and (ii) active $\mathrm{Fe}$ or $\mathrm{Co}$, which are desirable for preparation of N-C and $\mathrm{M}-\mathrm{N}-\mathrm{C}$ catalysts, respectively. Depending on the type of metal in MOF precursors, through a one-step carbonization at the elevated temperature (from 950 to $1100^{\circ} \mathrm{C}$ ) under inert gas atmosphere, the hydrocarbon networks in 3D framework MOFs can be directly converted into N-C or M-N-C catalysts. Although N-C catalysts have been demonstrated sufficient activity and stability for the ORR in alkaline media, addition of Fe or Co into MOF precursors is indispensable for yielding high activity in more challenging acidic media.

Compared to other studied nitrogen/carbon precursors, chemistry of MOF provides a great feasibility to allow us to design catalyst precursors by intentionally integrating various carbon, nitrogen, and metal sources into a well-defined and ordered 3D frameworks. These unique chemical and structural properties offers a great opportunity for engineering nanostructures and morphologies of PGM-free catalysts in terms of maximum density of active sites and optimal bonding structures in robust carbon matrix. Compared to many studied MOFs, Zn containing zeolitic imidazolate framework such as ZIF-8 is able to readily convert into highly porous nitrogen-doped carbon owing to the volatile nature of $\mathrm{Zn}$ at high temperatures. In addition, ZIFs have aromatic nature in imidazolate compounds and contain high nitrogen content, capable of forming $\mathrm{MN}_{4}$ coordination, which is crucial for generating ORR active $\mathrm{MN}_{\mathrm{x}}$ active sites (e.g., $\mathrm{CoN}_{\mathrm{x}}$ or $\mathrm{FeN}_{\mathrm{x}}$ ) during the carbonization as predicted from theoretical simulation. Furthermore, MOF composite precursors, which contain secondary nitrogen/metal sources, more than one type of MOF crystals, and additional supports/templates, were also designed for catalyst synthesis. The major motivation is to optimize resulting carbon phases with favorable structure and morphologies. It has been proved effective to further boost ORR activity by increasing density of active sites and surface areas through using MOF composite precursors. 
Currently, properly controlling Fe or Co contents into the ZIF-8 precursors with optimal $\mathrm{MN}_{4}$ content and local structural/chemical environments remains grand challenges to achieve maximum density of active sites embedded into carbon matrix. It has been found that excess Fe or Co in MOF precursors will lead to significant metallic or carbide aggregates rather than atomic dispersion of active metal sites [113][100], therefore reducing surface areas and porosity and mitigating ORR activity and stability. In addition, MOF crystal morphologies (size and particle shape) and distribution also play important role to affect the resulting carbon morphologies and structures of final catalysts. Usually, MOF crystals with smaller size and uniform dispersion onto templates are beneficial for the formation of optimal porosity, high surface area, and uniform distribution of active sites. Regarding the optimal carbon structures, the most highly active MOF-derived catalysts exhibited amorphous or less graphitization carbon. This is opposite to previous observation that highly graphitized nanocarbon structures in PGMfree catalysts is of importance. However, graphitized carbon in catalysts indeed facilitate to enhance corrosion resistance leading to an improvement of catalyst stability [138]. For instance, the decrease in the metal content resulted in high surface area and amorphous carbon with high ORR activity, but it showed fast degradation in the fuel cell stability test. Thus, it may suggest a balance between graphitization degree and surface area of carbon catalysts, which is necessary to achieve both high activity and good durability. Like other precursors-derived catalysts, MOFderived catalysts also need careful optimization of heating temperature, precursor ratios, and the way precursors interacted each other to achieve the maximum activity. These factors will affect the resulting intrinsic activity of sites, active site density, porosity/surface areas, and carbon corrosion resistance. It should be noted that it is difficult to control only one variable of the catalysts to correlate with the catalysts performance. Many factors such as the conductivity of the 
catalysts, metal contents, nitrogen contents, nitrogen types, different volume of pore size in the catalysts paly the overall role in affecting ORR activity. Thus, understanding the link among various factors will be greatly helpful to reach an optimal balance. Compared to active metal sites, nitrogen often is more than enough in catalysts. Increasing more active metal sites atomically dispersed into high-surface areas carbon phase is one of bottleneck to further improve current catalyst performance.

Asides from the activity, the stability of PGM-free ORR catalysts is another great challenge for the fuel cell applications, particularly in the more challenging acid electrolytes. Both the dopant oxidation (e.g, $\mathrm{N}$ or $\mathrm{Fe}$ ) and carbon corrosion need to be considered in order to address the stability issue. Due to the possible Fenton agent effects, the existence of large amount metals, metal oxides and metal carbides are not favorable for obtaining stable fuel cell performance. Thus, such metallic compositions should be minimized in the preparation of the stable ORR cathode. Several strategies can be applied to reduce the formation of unstable metallic compounds by controlling the amounts of metal precursors and well-dispersing metals in MOFs precursors and choosing aromatic ligands possibly beneficial to strengthen the bonding between metal and nitrogen. In terms of nitrogen-doped carbon components, highly graphitized carbon is preferred for the improving the stability. Therefore, to improve the stability by using MOFs precursors, properly increasing graphitization degree of carbon through higher temperatures is desirable. In addition, apart from extensively studied Fe and Co-based PGM-free catalysts, Mn represents a new opportunity to design highly stable and active, but iron-free catalysts. Such possibility has been predicted by recent experimental and theoretical efforts [81], which authors are still focusing on. However, a grand challenge is to develop feasible synthesis approaches to increasing density of active sites by properly engineering catalyst morphology and structures. 
Although the MOF crystal itself has well-defined chemical and structural properties, the complex reactions occurring during the catalyst synthesis at high temperature still cause many uncertainty; the detailed mechanism of active site formation remain unknown. Therefore, one of future focus is to understand the formation mechanism of active sites associated with hightemperature carbonization by using sensitive in-situ characterization such as XRD, Raman, and XAS. Apart from developing high-performance PGM-free catalysts, the well-defined MOF crystal structures can be ideal model systems to help elucidate precursor-catalyst correlation. Unlike traditional carbon catalysts containing highly heterogeneous morphology [140], homogeneous N-C or M-N-C catalyst can be prepared from well-defined MOF crystal precursors. Formation of inactive metallic aggregates can be eliminated. By intentionally controlling the doping content of $\mathrm{Fe}$ or $\mathrm{Co}$ and their local chemistry in MOFs, the number of active sites and bonding structures can be tuned to certain degree. This will allow us exclusively and accurately probing the transition metals ( $\mathrm{Fe}$ or $\mathrm{Co}$ )-related active sties and elucidate the nature of PGM-free catalysts, which has been a puzzle in the field for decades.

\section{Acknowledgment}

G. Wu acknowledges the Start-up funding from the University at Buffalo (SUNY) along with NSF (CBET-1604392) and U.S. Department of Energy, Fuel Cell Technologies Office (FCTO) Incubator Program (DE-EE000696). The work at Pacific Northwest National Laboratory (PNNL) was supported by DOE Fuel Cell Technologies Office. PNNL is operated by Battelle for the Department of Energy under Contract DE-AC05-76RLO1830.

\section{References}

[1] S. Sharma, S.K. Ghoshal, Renewable and Sustainable Energy Reviews, 43 (2015) 1151-1158. 
[2] H.A. Gasteiger, S.S. Kocha, B. Sompalli, F.T. Wagner, Applied Catalysis B: Environmental, 56 (2005) 9-35.

[3] M. Shao, Q. Chang, J.-P. Dodelet, R. Chenitz, Chemical Reviews, 116 (2016) 3594-3657.

[4] L. Carrette, K.A. Friedrich, U. Stimming, Fuel Cells, 1 (2001) 5-39.

[5] A. Serov, K. Artyushkova, E. Niangar, C. Wang, N. Dale, F. Jaouen, M.-T. Sougrati, Q. Jia, S. Mukerjee, P. Atanassov, Nano Energy, 16 (2015) 293-300.

[6] Y. Shao, G. Yin, Y. Gao, Journal of Power Sources, 171 (2007) 558-566.

[7] Q. Li, L. Wu, G. Wu, D. Su, H. Lv, S. Zhang, W. Zhu, A. Casimir, H. Zhu, A. MendozaGarcia, Nano Letters, 15 (2015) 2468-2473.

[8] Q. Li, X. Wen, G. Wu, H. Chung, P. Zelenay, Angew. Chem. Int. Ed, 54 (2015) 7524-7528.

[9] C. Chen, Y. Kang, Z. Huo, Z. Zhu, W. Huang, H.L. Xin, J.D. Snyder, D. Li, J.A. Herron, M. Mavrikakis, Science, 343 (2014) 1339-1343.

[10] L. Gan, C. Cui, M. Heggen, F. Dionigi, S. Rudi, P. Strasser, Science, 346 (2014) 1502-1506.

[11] Q. Li, H. Pan, D. Higgins, R. Cao, G. Zhang, H. Lv, K. Wu, J. Cho, G. Wu, Small, 11 (2015) $1443-1452$.

[12] G. Wu, K.L. More, C.M. Johnston, P. Zelenay, Science, 332 (2011) 443-447.

[13] K. Gong, F. Du, Z. Xia, M. Durstock, L. Dai, science, 323 (2009) 760-764.

[14] M. Lefèvre, E. Proietti, F. Jaouen, J.-P. Dodelet, Science, 324 (2009) 71-74.

[15] F. Jaouen, E. Proietti, M. Lefèvre, R. Chenitz, J.-P. Dodelet, G. Wu, H.T. Chung, C.M. Johnston, P. Zelenay, Energy Environ. Sci., 4 (2011) 114-130.

[16] Z. Chen, D. Higgins, A. Yu, L. Zhang, J. Zhang, Energy \& Environmental Science, 4 (2011) 3167-3192.

[17] H.T. Chung, J.H. Won, P. Zelenay, Nature communications, 4 (2013) 1922. 
[18] S. Gupta, W. Kellogg, H. Xu, X. Liu, J. Cho, G. Wu, Chemistry - An Asian Journal, 11 (2016) 10-21.

[19] X. Liu, M. Park, M.G. Kim, S. Gupta, X. Wang, G. Wu, J. Cho, Nano Energy, 20 (2016) $315-325$.

[20] X. Liu, M. Park, M.G. Kim, S. Gupta, G. Wu, J. Cho, Angew. Chem.-Int. Edit., 54 (2015) 9654-9658.

[21] X. Liu, W. Liu, M. Ko, S. Chae, S. Park, A. Casimir, G. Wu, J. Cho, Advanced Functional Materials, 25 (2015) 5799-5808.

[22] X. Wang, Y. Ke, H. Pan, K. Ma, Q. Xiao, G. Wu, M.T. Swihart, ACS Catalysis, 5 (2015) $2534-2540$.

[23] C.-F. Chen, G. King, R.M. Dickerson, P.A. Papin, S. Gupta, W.R. Kellogg, G. Wu, Nano Energy, 13 (2015) 423-432.

[24] H. Osgood, S.V. Devaguptapu, H. Xu, J.P. Cho, G. Wu, Nano Today, 11 (2016) doi:10.1016/j.nantod.2016.1009.1001.

[25] H. Sheng, M. Wei, A. D’Aloia, G. Wu, ACS Applied Materials \& Interfaces, 8 (2016) $30212-30224$.

[26] G. Wu, A. Santandreu, W. Kellogg, S. Gupta, O. Ogoke, H. Zhang, H.-L. Wang, L. Dai, Nano Energy, 29 (2016) doi:10.1016/j.nanoen.2015.1012.1032.

[27] R. Jasinski, Nature, 201 (1964) 1212 - 1213.

[28] H. Jahnke, M. Schönborn, G. Zimmermann, Physical and chemical applications of dyestuffs, (1976) 133-181.

[29] S. Gupta, D. Tryk, I. Bae, W. Aldred, E. Yeager, Journal of Applied Electrochemistry, 19 (1989) 19-27. 
[30] F. Jaouen, S. Marcotte, J.-P. Dodelet, G. Lindbergh, The Journal of Physical Chemistry B, 107 (2003) 1376-1386.

[31] F. Jaouen, F. Charreteur, J.P. Dodelet, Journal of The Electrochemical Society, 153 (2006) A689-A698.

[32] M. Lefèvre, J.P. Dodelet, P. Bertrand, The Journal of Physical Chemistry B, 104 (2000) $11238-11247$.

[33] F. Jaouen, A.M. Serventi, M. Lefèvre, J.-P. Dodelet, P. Bertrand, The Journal of Physical Chemistry C, 111 (2007) 5971-5976.

[34] R. Bashyam, P. Zelenay, Nature, 443 (2006) 63-66.

[35] G. Wu, M.A. Nelson, N.H. Mack, S. Ma, P. Sekhar, F.H. Garzon, P. Zelenay, Chem. Commun. , 46 (2010) 7489-7491.

[36] G. Wu, K. Artyushkova, M. Ferrandon, A.J. Kropf, D. Myers, P. Zelenay, ECS Transactions, 25 (2009) 1299-1311.

[37] V. Nallathambi, J.-W. Lee, S.P. Kumaraguru, G. Wu, B.N. Popov, Journal of Power Sources, 183 (2008) 34-42.

[38] G. Wu, Z. Chen, K. Artyushkova, F.H. Garzon, P. Zelenay, ECS Transactions, 16 (2008) 159-170.

[39] L. Qu, Y. Liu, J.-B. Baek, L. Dai, ACS Nano, 4 (2010) 1321-1326.

[40] X. Wang, H. Fu, W. Li, J. Zheng, X. Li, RSC Advances, 4 (2014) 37779-37785.

[41] Q. Li, G. Wu, D.A. Cullen, K.L. More, N.H. Mack, H. Chung, P. Zelenay, ACS Catalysis, 4 (2014) 3193-3200. 
[42] U.I. Kramm, J. Herranz, N. Larouche, T.M. Arruda, M. Lefevre, F. Jaouen, P. Bogdanoff, S. Fiechter, I. Abs-Wurmbach, S. Mukerjee, J.-P. Dodelet, Physical Chemistry Chemical Physics, 14 (2012) 11673-11688.

[43] M. Lefèvre, J.P. Dodelet, P. Bertrand, The Journal of Physical Chemistry B, 109 (2005) 16718-16724.

[44] M. Lefèvre, J.P. Dodelet, P. Bertrand, The Journal of Physical Chemistry B, 106 (2002) $8705-8713$.

[45] U.I. Kramm, M. Lefèvre, N. Larouche, D. Schmeisser, J.-P. Dodelet, Journal of the American Chemical Society, 136 (2014) 978-985.

[46] F. Jaouen, M. Lefèvre, J.-P. Dodelet, M. Cai, The Journal of Physical Chemistry B, 110 (2006) 5553-5558.

[47] Q. Li, R. Cao, J. Cho, G. Wu, Phys. Chem. Chem. Phys., 16 (2014) 13568 - 13582.

[48] Y. Shao, J. Sui, G. Yin, Y. Gao, Applied Catalysis B: Environmental, 79 (2008) 89-99.

[49] F. Jaouen, E. Proietti, M. Lefevre, R. Chenitz, J.-P. Dodelet, G. Wu, H.T. Chung, C.M. Johnston, P. Zelenay, Energy \& Environmental Science, 4 (2011) 114-130.

[50] G. Wu, P. Zelenay, Accounts of Chemical Research, 46 (2013) 1878-1889.

[51] E.F. Holby, P. Zelenay, Nano Energy, http://dx.doi.org/10.1016/j.nanoen.2016.1005.1025.

[52] Z. Duan, G. Wang, Physical Chemistry Chemical Physics, 13 (2011) 20178-20187.

[53] S. Kattel, G. Wang, J Mater Chem A, 1 (2013) 10790-10797.

[54] E.F. Holby, G. Wu, P. Zelenay, C.D. Taylor, J. Phys. Chem. C, 118 (2014) 14388-14393.

[55] G. Wu, M. Nelson, S. Ma, H. Meng, G. Cui, P.K. Shen, Carbon, 49 (2011) 3972-3982. 
[56] M. Ferrandon, A.J. Kropf, D.J. Myers, K. Artyushkova, U. Kramm, P. Bogdanoff, G. Wu, C.M. Johnston, P. Zelenay, The Journal of Physical Chemistry C, 116 (2012) 16001 16013.

[57] F. Jaouen, J. Herranz, M. Lefèvre, J.-P. Dodelet, U.I. Kramm, I. Herrmann, P. Bogdanoff, J. Maruyama, T. Nagaoka, A. Garsuch, J.R. Dahn, T. Olson, S. Pylypenko, P. Atanassov, E.A. Ustinov, ACS Applied Materials \& Interfaces, 1 (2009) 1623-1639.

[58] W. Gao, D. Havas, S. Gupta, Q. Pan, N. He, H. Zhang, H.-L. Wang, G. Wu, Carbon, 102 (2016) 346-356.

[59] Q. Li, T. Wang, D. Havas, H. Zhang, P. Xu, J. Han, J. Cho, G. Wu, Advanced Science, (2016) doi:10.1002/advs.201600140.

[60] S. Gupta, L. Qiao, S. Zhao, Y. Lin, D.S. Vamsi, H. Xu, X. Wang, M. Swihart, G. Wu, Advanced Energy Materials, (2016) doi:10.1002/aenm.201601198.

[61] F.-L. Meng, Z.-L. Wang, H.-X. Zhong, J. Wang, J.-M. Yan, X.-B. Zhang, Advanced Materials, 28 (2016) 7948-7955.

[62] W.-J. Jiang, L. Gu, L. Li, Y. Zhang, X. Zhang, L.-J. Zhang, J.-Q. Wang, J.-S. Hu, Z. Wei, L.-J. Wan, Journal of the American Chemical Society, 138 (2016) 3570-3578.

[63] Z.-L. Wang, D. Xu, H.-X. Zhong, J. Wang, F.-L. Meng, X.-B. Zhang, Science Advances, 1 (2015) 10.1126/sciadv.1400035.

[64] H. Furukawa, K.E. Cordova, M. O’Keeffe, O.M. Yaghi, Science, 341 (2013) 1230444.

[65] J. Lee, O.K. Farha, J. Roberts, K.A. Scheidt, S.T. Nguyen, J.T. Hupp, Chemical Society Reviews, 38 (2009) 1450-1459.

[66] S.-L. Li, Q. Xu, Energy \& Environmental Science, 6 (2013) 1656-1683. 
[67] B. Liu, H. Shioyama, T. Akita, Q. Xu, Journal of the American Chemical Society, 130 (2008) 5390-5391.

[68] H.-L. Jiang, B. Liu, Y.-Q. Lan, K. Kuratani, T. Akita, H. Shioyama, F. Zong, Q. Xu, Journal of the American Chemical Society, 133 (2011) 11854-11857.

[69] S.J. Yang, T. Kim, J.H. Im, Y.S. Kim, K. Lee, H. Jung, C.R. Park, Chemistry of Materials, 24 (2012) 464-470.

[70] G. Goenaga, S. Ma, S. Yuan, D.-J. Liu, ECS Transactions, 33 (2010) 579-586.

[71] A. Zitolo, V. Goellner, V. Armel, M.-T. Sougrati, T. Mineva, L. Stievano, E. Fonda, F. Jaouen, Nat. Mater., 14 (2015) 937-942.

[72] J. Shui, C. Chen, L. Grabstanowicz, D. Zhao, D.J. Liu, Proceedings of the National Academy of Sciences of the United States of America, 112 (2015) 10629-10634.

[73] E. Proietti, F. Jaouen, M. Lefèvre, N. Larouche, J. Tian, J. Herranz, J.-P. Dodelet, Nat. Commun., 2 (2011) 416.

[74] H.X. Zhong, J. Wang, Y.W. Zhang, W.L. Xu, W. Xing, D. Xu, Y.F. Zhang, X.B. Zhang, Angew Chem Int Edit, 53 (2014) 14235-14239.

[75] L. Ge, Y. Yang, L. Wang, W. Zhou, R. De Marco, Z. Chen, J. Zou, Z. Zhu, Carbon, 82 (2015) 417-424.

[76] J. Mao, L. Yang, P. Yu, X. Wei, L. Mao, Electrochem. Commun., 19 (2012) 29-31.

[77] J. Yang, F. Zhao, B. Zeng, RSC Advances, 5 (2015) 22060-22065.

[78] M. Ferrandona, X. Wang, A.J. Kropfa, D.J. Myersa, G. Wu, C.M. Johnston, P. Zelenay, Electrochimica Acta, 110 (2013) 282-291.

[79] Q. Jia, N. Ramaswamy, H. Hafiz, U. Tylus, K. Strickland, G. Wu, B. Barbiellini, A. Bansil, E.F. Holby, P. Zelenay, ACS Nano, 9 (2015) 12496-12505. 
[80] G. Zhang, R. Chenitz, M. Lefèvre, S. Sun, J.-P. Dodelet, Nano Energy, http://dx.doi.org/10.1016/j.nanoen.2016.1002.1038.

[81] D. Higgins, G. Wu, H.T. Chung, U. Martinez, S. Ma, Z. Chen, P. Zelenay, ECS Transactions, 61 (2014) 35-42.

[82] R. Banerjee, H. Furukawa, D. Britt, C. Knobler, M. O’Keeffe, O.M. Yaghi, Journal of the American Chemical Society, 131 (2009) 3875-3877.

[83] N.L. Rosi, J. Kim, M. Eddaoudi, B. Chen, M. O'Keeffe, O.M. Yaghi, Journal of the American Chemical Society, 127 (2005) 1504-1518.

[84] X.J. Wang, J.W. Zhou, H. Fu, W. Li, X.X. Fan, G.B. Xin, J. Zheng, X.G. Li, J Mater Chem A, 2 (2014) 14064-14070.

[85] A. Phan, C.J. Doonan, F.J. Uribe-Romo, C.B. Knobler, M. O’Keeffe, O.M. Yaghi, Accounts of Chemical Research, 43 (2010) 58-67.

[86] K.S. Park, Z. Ni, A.P. Côté, J.Y. Choi, R. Huang, F.J. Uribe-Romo, H.K. Chae, M. O’Keeffe, O.M. Yaghi, Proceedings of the National Academy of Sciences, 103 (2006) 10186-10191.

[87] S. Ma, G.A. Goenaga, A.V. Call, D.-J. Liu, Chemistry - A European Journal, 17 (2011) 2063-2067.

[88] W. Xia, J.H. Zhu, W.H. Guo, L. An, D.G. Xia, R.Q. Zou, J Mater Chem A, 2 (2014) 1160611613.

[89] L. Zhang, Z. Su, F. Jiang, L. Yang, J. Qian, Y. Zhou, W. Li, M. Hong, Nanoscale, 6 (2014) 6590-6602.

[90] X. Ma, X. Zhao, J. Sun, D. Liab, X. Yang, RSC Advances, 6 (2016) 7728-7735. 
[91] D.Y. Chung, K.J. Lee, S.-H. Yu, M. Kim, S.Y. Lee, O.-H. Kim, H.-J. Park, Y.-E. Sung, Advanced Energy Materials, 5 (2015) 10.1002/aenm.201401309.

[92] L. Shang, H. Yu, X. Huang, T. Bian, R. Shi, Y. Zhao, G.I.N. Waterhouse, L.-Z. Wu, C.-H. Tung, T. Zhang, Advanced Materials, 28 (2016) 1668-1674.

[93] W. Zhang, Z.Y. Wu, H.L. Jiang, S.H. Yu, Journal of the American Chemical Society, 136 (2014) 14385-14388.

[94] Q. Luo, L. Chen, B. Duan, Z. Gu, J. Liu, M. Xu, C. Duan, RSC Advances, 6 (2016) 1246712471.

[95] S. Pandiaraj, H.B. Aiyappa, R. Banerjee, S. Kurungot, Chem. Commun. , 50 (2014) 3363 3366.

[96] J.-S. Li, S.-L. Li, Y.-J. Tang, K. Li, L. Zhou, N. Kong, Y.-Q. Lan, J.-C. Bao, Z.-H. Dai, Sci. Rep., 4 (2014) 5130.

[97] X. Zhao, H. Zhao, T. Zhang, X. Yan, Y. Yuan, H. Zhang, H. Zhao, D. Zhang, G. Zhu, X. Yao, J Mater Chem A, 2 (2014) 11666-11671.

[98] Y.Z. Chen, C. Wang, Z.Y. Wu, Y. Xiong, Q. Xu, S.H. Yu, H.L. Jiang, Adv. Mater. , 27 (2015) 5010-5016.

[99] B. You, N. Jiang, M. Sheng, W.S. Drisdell, J. Yano, Y. Sun, ACS Catalysis, 5 (2015) 70687076.

[100] X. Wang, X. Fan, H. Lin, H. Fu, T. Wang, J. Zheng, X. Li, RSC Advances, 6 (2016) 37965-37973.

[101] Q.-L. Zhu, W. Xia, T. Akita, R. Zou, Q. Xu, Advanced Materials, 28 (2016) 6391-6398.

[102] H. Hu, L. Han, M. Yu, Z. Wang, X.W. Lou, Energy \& Environmental Science, 9 (2016) 107-111. 
[103] Z. Li, M. Shao, L. Zhou, Q. Yang, C. Zhang, M. Wei, D.G. Evans, X. Duan, Nano Energy, 25 (2016) 100-109.

[104] A. Kong, C. Mao, Q. Lin, X. Wei, X. Bu, P. Feng, Dalton Transactions, 44 (2015) 67486754.

[105] F. Bai, H. Huang, C. Hou, P. Zhang, New J. Chem., 40 (2016) 1679-1684.

[106] T. Liu, P. Zhao, X. Hua, W. Luo, S. Chen, G. Cheng, J Mater Chem A, 4 (2016) $11357-$ 11364.

[107] Y. Wu, S. Zhao, K. Zhao, T. Tu, J. Zheng, J. Chen, H. Zhou, D. Chen, S. Li, J. Power Sources, 311 (2016) 137-143.

[108] K. Strickland, E. Miner, Q. Jia, U. Tylus, N. Ramaswamy, W. Liang, M.-T. Sougrati, F. Jaouen, S. Mukerjee, Nat. Commun., 6 (2015) 10.1038/ncomms8343.

[109] P. Su, H. Xiao, J. Zhao, Y. Yao, Z. Shao, C. Li, Q. Yang, Chemical Science, 4 (2013) 2941-2946.

[110] C. Mao, A. Kong, Y. Wang, X. Bu, P. Feng, Nanoscale, 7 (2015) 10817-10822.

[111] Q. Li, P. Xu, W. Gao, S. Ma, G. Zhang, R. Cao, J. Cho, H.L. Wang, G. Wu, Adv. Mater. , 26 (2014) 1378-1386.

[112] L. Chong, G.A. Goenaga, K. Williams, H.M. Barkholtz, L.R. Grabstanowicz, A.B. Papandrew, R. Elzein, R. Schlaf, T.A. Zawodzinski Jr, J. Zou, S. Ma, D.-J. Liu, ChemElectroChem, (2016) 10.1002/celc.201600163.

[113] X. Wang, H. Zhang, H. Lin, S. Gupta, C. Wang, Z. Tao, H. Fu, T. Wang, J. Zheng, G. Wu, X. Li, Nano Energy, 25 (2016) 110-119.

[114] A. Morozan, M.T. Sougrati, V. Goellner, D. Jones, L. Stievano, F. Jaouen, Electrochimica Acta, 119 (2014) 192-205. 
[115] D. Zhao, J.L. Shui, C. Chen, X.Q. Chen, B.M. Reprogle, D.P. Wang, D.J. Liu, Chemical Science, 3 (2012) 3200-3205.

[116] D. Zhao, J.-L. Shui, L.R. Grabstanowicz, C. Chen, S.M. Commet, T. Xu, J. Lu, D.-J. Liu, Advanced Materials, 26 (2014) 1093-1097.

[117] T. Palaniselvam, B.P. Biswal, R. Banerjee, S. Kurungot, Chem-Eur J, 19 (2013) 93359342.

[118] N.P. Subramanian, X. Li, V. Nallathambi, S.P. Kumaraguru, H. Colon-Mercado, G. Wu, J.-W. Lee, B.N. Popov, Journal of Power Sources, 188 (2009) 38-44.

[119] Q. Li, R. Cao, J. Cho, G. Wu, Advanced Energy Materials, 4 (2014) 1301415.

[120] Z.-L. Wang, D. Xu, J.-J. Xu, X.-B. Zhang, Chemical Society Reviews, 43 (2014) 77467786.

[121] H.-x. Zhong, K. Li, Q. Zhang, J. Wang, F.-1. Meng, Z.-j. Wu, J.-m. Yan, X.-b. Zhang, NPG Asia Mater, 8 (2016) e308.

[122] J.J. Xu, D. Xu, Z.L. Wang, H.G. Wang, L.L. Zhang, X.B. Zhang, Angewandte Chemie International Edition, 52 (2013) 3887-3890.

[123] Q. Li, P. Xu, B. Zhang, H. Tsai, J. Wang, H.-L. Wang, G. Wu, Chemical Communications, 49 (2013) 10838-10840.

[124] D. Eisenberg, W. Stroek, N.J. Geels, S. Tanase, M. Ferbinteanu, S.J. Teat, P. Mettraux, N. Yan, G. Rothenberg, Physical Chemistry Chemical Physics, 18 (2016) 20778-20783.

[125] C.W.B. Bezerra, L. Zhang, K. Lee, H. Liu, A.L.B. Marques, E.P. Marques, H. Wang, J. Zhang, Electrochimica Acta, 53 (2008) 4937-4951.

[126] F. Afsahi, S. Kaliaguine, J Mater Chem A, 2 (2014) 12270-12279. 
[127] G. Wu, C.M. Johnston, N.H. Mack, K. Artyushkova, M. Ferrandon, M. Nelson, J.S. Lezama-Pacheco, S.D. Conradson, K.L. More, D.J. Myers, Journal of Materials Chemistry, $21(2011)$ 11392-11405.

[128] U.I. Kramm, I. Herrmann-Geppert, J. Behrends, K. Lips, S. Fiechter, P. Bogdanoff, Journal of the American Chemical Society, 138 (2016) 635-640.

[129] Y. Qian, J. Cavanaugh, I.A. Khan, X. Wang, Y. Peng, Z. Hu, Y. Wang, D. Zhao, ChemPlusChem, (2016) 10.1002/cplu.201600174.

[130] G. Wu, N.H. Mack, W. Gao, S. Ma, R. Zhong, J. Han, J.K. Baldwin, P. Zelenay, ACS Nano, 6 (2012) 9764-9776.

[131] Q. Li, P. Xu, W. Gao, S. Ma, G. Zhang, R. Cao, J. Cho, H.-L. Wang, G. Wu, Advanced Materials, 26 (2014) 1378-1386.

[132] J.-P. Dodelet, R. Chenitz, L. Yang, M. Lefèvre, ChemCatChem, 6 (2014) 1866-1867.

[133] S. Pandiaraj, H.B. Aiyappa, R. Banerjee, S. Kurungot, Chem. Commun. (Cambridge, U. K.), 50 (2014) 3363-3366.

[134] G. Wu, H.T. Chung, M. Nelson, K. Artyushkova, K.L. More, C.M. Johnston, P. Zelenay, ECS Transactions, 41 (2011) 1709-1717.

[135] U.I. Kramm, M. Lefèvre, P. Bogdanoff, D. Schmeißer, J.-P. Dodelet, The Journal of Physical Chemistry Letters, 5 (2014) 3750-3756.

[136] H.M. Barkholtz, L.N. Chong, Z.B. Kaiser, T. Xu, D.J. Liu, Catalysts, 5 (2015) 955-965.

[137] Q. He, Q. Li, S. Khene, X. Ren, A. Bueno-López, G. Wu, The Journal of Physical Chemistry C, 117 (2013) 8697-8707.

[138] G. Wu, K.L. More, P. Xu, H.-L. Wang, M. Ferrandon, A.J. Kropf, D.J. Myers, S. Ma, P. Zelenay, Chem. Commun., 49 (2013) 3291-3293. 
[139] X. Wang, Q. Li, H. Pan, Y. Lin, Y. Ke, H. Sheng, M.T. Swihart, G. Wu, Nanoscale, 7 (2015) 20290-20298.

[140] H.T. Chung, G. Wu, Q. Li, P. Zelenay, International Journal of Hydrogen Energy, 39 (2014) 15887-15893. 


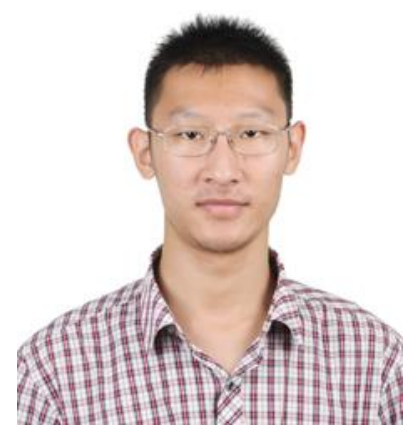

Hanguang Zhang is a Ph.D. student at University at Buffalo (UB), SUNY. He obtained his Bachelor and Master degrees from Sichuan University (2013) and UB (2015), respectively. His currently research in Prof Gang Wu's group is to develop highly efficient three-dimensional porous carbon materials for energy conversion and storage.

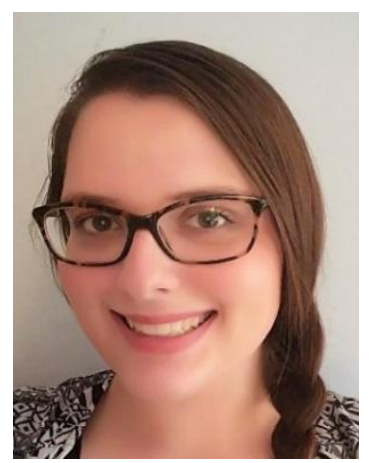

Hannah Osgood born in 1993 and is a 2016 graduate from the Undergraduate Chemical Engineering program at the University at Buffalo (UB), SUNY. She began researching carbon and oxides electrocatalysts with Professor Gang Wu during her senior year at UB. After graduated in the summer of 2016, Hannah has accepted a position in Rochester, New York, researching cadmium-free phosphors for lighting and electronics to improve their efficiency and optical-flux stability.

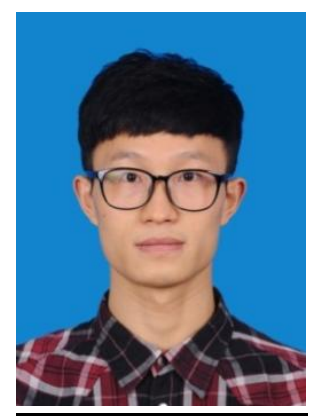

Xiaohong Xie is a Ph.D. candidate in the School of Chemistry and Chemical engineering at Chongqing University. He received a B.S. degree in Materials Chemistry from Nanchang Hangkong University in 2011. His main research interests lie in the development of low-Pt materials with rational modification 
for ORR and non-precious catalysts for HER in electrocatalysis application. He is currently a visiting scholar at Pacific Northwest National Laboratory.

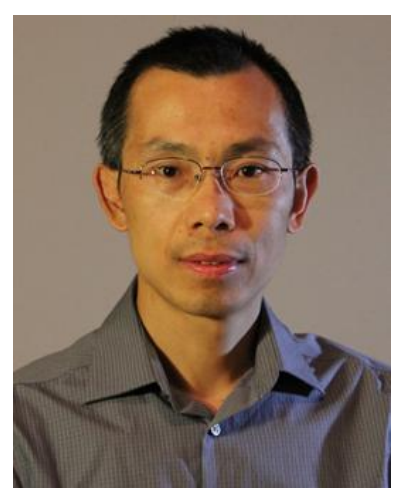

Dr. Yuyan Shao received his Ph.D. from Harbin Institute of Technology. He is now a Senior Scientist at the US DOE Pacific Northwest National Laboratory. His research focus is materials science and materials chemistry for electrochemical energy conversion and storage, including fuel cells and batteries.

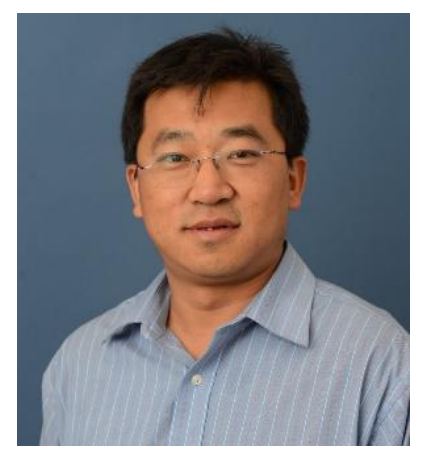

Gang $\mathbf{W u}$ is an Assistant Professor in the Department of Chemical and Biological Engineering at the University at Buffalo (UB), SUNY. He obtained his Ph.D. at the Harbin Institute of Technology in 2004 followed by extensive postdoctoral trainings at Tsinghua University (2004-2006), the University of South Carolina (2006-2008), and Los Alamos National Laboratory (LANL) (2008-2010). Then, he was a staff scientist at LANL until he joined UB in fall of 2014 when he started his academic career. He is trained in electrochemical engineering at the very beginning from undergraduate education and his current research still focuses on electrochemical energy and environmental applications with an emphasis on the development of functional electrocatalysts and energy storage materials. 
Graphic abstract:

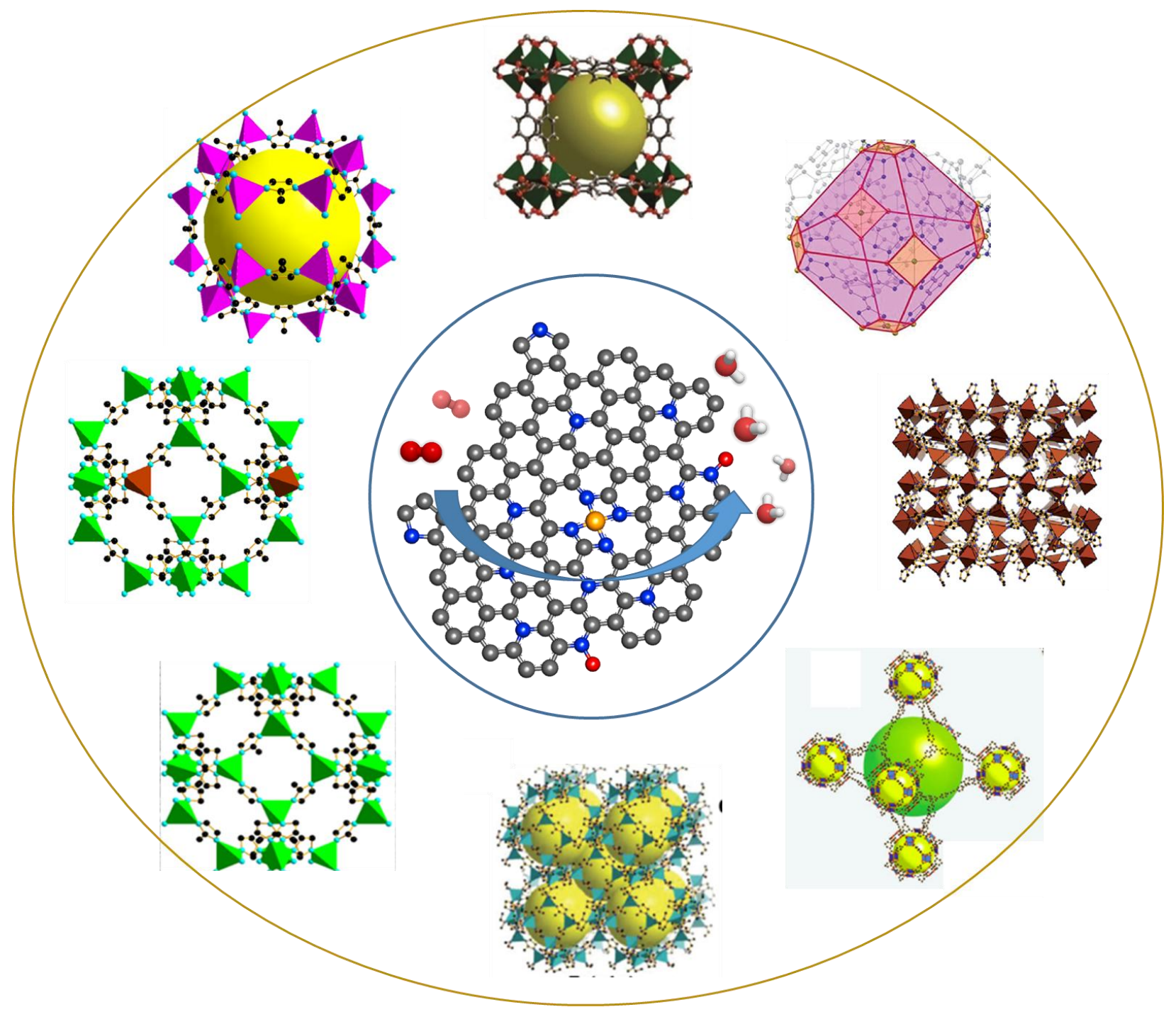

